\title{
Phylogeny, Morphology, Distribution, and Pathogenicity of Botryosphaeriaceae and Diaporthaceae from English Walnut in California
}

ShuaiFei Chen and David P. Morgan, Department of Plant Pathology, University of California-Davis/Kearney Agricultural Research
and Extension Center, Parlier 93648; Janine K. Hasey, University of California Cooperative Extension, Yuba/Sutter Co., Yuba City
95991; Kathleen Anderson, University of California Cooperative Extension, Stanislaus Co., Modesto 95358; and Themis J. Michailides, Department of Plant Pathology, University of California-Davis/Kearney Agricultural Research and Extension Center

\begin{abstract}
Chen, S. F., Morgan, D. P., Hasey, J. K., Anderson, K., and Michailides, T. J. 2014. Phylogeny, morphology, distribution, and pathogenicity of Botryosphaeriaceae and Diaporthaceae from English walnut in California. Plant Dis. 98:636-652.

Species of family Botryosphaeriaceae and genus Diaporthe (anamorph: genus Phomopsis, family Diaporthaceae) were reported and caused diseases on various fruit and nut trees in California. In the last several years, diseases on English walnut (Juglans regia) caused by species of Botryosphaeriaceae and Diaporthe were observed frequently in California. Disease symptoms include stem canker; shoot canker and blight; twig, leaf, and fruit blight; and necrotic leaf lesions. Isolates of the pathogen were collected from English walnut in 13 counties in California. The aims of this study were to identify these isolates and to test their pathogenicity to English walnut cultivars. In total, $159 \mathrm{Cal}-$ ifornia isolates were identified based on comparisons of DNA sequence data of the internal transcribed spacer, translation elongation factor 1- $\alpha$, and $\beta$-tubulin gene regions, and combined with the morphological features of the cultures and conidia. Research results revealed

that isolates represent 10 species of Botryosphaeriaceae and two species of Diaporthe. These species include Botryosphaeria dothidea, Diplodia mutila, D. seriata, Dothiorella iberica, Lasiodiplodia citricola, Neofusicoccum mediterraneum, $N$. nonquaesitum, $N$. parvum, $N$. vitifusiforme, Neoscytalidium dimidiatum, Diaporthe neotheicola, and $D$. rhusicola. Pathogenicity on three English walnut cultivars ('Chandler', 'Tulare', and 'Vina') using a mycelium plug inoculation method revealed that all these species are pathogenic to all the tested cultivars, with $L$. citricola and $N$. parvum being the most pathogenic species, followed by $N$. mediterraneum, $N$. dimidiatum, and $B$. dothidea. Chandler was more tolerant to infection than Tulare and Vina. Results in this study determined that multiple numbers of the Botryosphaeriaceae fungi and two Diaporthe spp. cause cankers and blights of English walnut and vary in their virulence from highly to slightly virulent, respectively.
\end{abstract}

Walnut seed are a high-density source of nutrients, particularly proteins and essential fatty acids. The two most common major species of walnut are grown for their seed-the Black walnut ( $J u$ glans nigra) and the English walnut (J. regia; 9). The Black walnut is of high flavor but, due to its hard shell and poor hulling characteristics, it is not grown commercially for nut production (9). The commercially produced walnut varieties are nearly all hybrids of the English walnut (9). The worldwide production of walnut seed has been increasing rapidly in recent years. In 2011, the world's three largest producers of inshell walnut seed were China (1.65 million metric tons [t]), Iran (0.49 million $\mathrm{t})$, and the United States (0.42 million t) (21). In California, there are approximately 89,000 ha of English walnut with $>30$ cultivars planted, producing $99 \%$ of English walnut seed in the United States $(9,57)$. Almost all production takes place in the two major Sacramento and San Joaquin Valleys of California (9).

Members of the family Botryosphaeriaceae (Botryosphaeriales) have a worldwide distribution and cause disease on a wide variety of woody plants $(8,54)$. In California, Botryosphaeriaceae fungi have been reported and caused diseases on many important fruit and nut trees, such as almond (Prunus dulcis; 28), avocado (Persea americana; 33,34), grapevine (Vitis vinifera; 61-63), olive (Olea europaea; 41,65), and pistachio (Pistacia vera; 32,36). The disease symptoms caused by Botryosphaeriaceae fungi on fruit and nut trees in California include stem and branch canker, shoot blight, twig and fruit blight, bud blight, and twig dieback and leaf blight $(28,32,33,36,41,63-65)$. For the California fruit and nut trees,

Corresponding author: T. J. Michailides, E-mail: tjmichailides@ucanr.edu

Accepted for publication 7 November 2013.

http://dx.doi.org/10.1094/PDIS-07-13-0706-RE

(c) 2014 The American Phytopathological Society some species of Botryosphaeriaceae are considered as important pathogens; for example Lasiodiplodia citricola $(11,14)$, L. theobromae $(13,61)$ and Neofusicoccum parvum $(28,34,61)$ are highly pathogenic to their hosts, $N$. mediterraneum is widely distributed and moderately pathogenic to almond (28).

The genus Phomopsis (anamorph of Diaporthe) contains $>1,000$ species names, which comprise important phytopathogenic microfungi from a wide ranges of hosts $(24,48,58,59)$. For species identification in the genera Diaporthe and Phomopsis, the traditional methods, including morphology, culture characteristics, and host association, are inadequate or unreliable $(24,50,58)$. Recently, molecular technologies have been used to identify species of $\mathrm{Di}$ aporthe or Phomopsis effectively and credibly $(24,50,58)$. We are now able to link anamorph and teleomorph states through molecular sequence data regardless of whether the taxon in question expresses sexual or asexual structures $(24,26,27,49,52,69)$. There is a movement underway to provide all fungal species with a single name $(26,27,52,69)$. In this study, we have chosen to use the sexual name (Diaporthe), the older name (Diaporthe in 1870 versus Phomopsis in 1905), for the species of Diaporthe or Phomopsis.

In California, species of Diaporthe cause stem and branch cankers, shoot blight, twig dieback, fruit rot, leaf spot and blight to a wide range of plant hosts $(22,42)$. Diaporthe spp. have been reported on various nut crops and fruits, such as almond (2), avocado (22), fig (37), olive (65), pistachio $(16,22,39)$ and strawberry (Fragaria $\times$ ananassa; 22 ). Recent inoculation results indicated that species of Diaporthe were considered as weak pathogens to olive in California (65).

The limited research about diseases on English walnut in California has resulted in identification of five species of Botryosphaeriaceae, include Diplodia seriata, L. citricola, N. mediterraneum, N. parvum and Neoscytalidium dimidiatum (11,28). All these species were isolated from diseased walnut stems, branches or twigs. Pathogenicity tests indicated that they are all pathogenic to English walnut branches (11) and L. citricola and/or N. dimidia- 
tum were able to kill the walnut graft union in a commercial nursery in California (11). These results suggested that members of the family Botryosphaeriaceae constitute a threat to the English walnut industry in California.

In California, during the last several years, a mass of diseased walnut samples from various counties where English walnut are grown were collected, and the relative fungi with the typical morphological characteristics of family Botryosphaeriaceae or genus Diaporthe were isolated. The objectives of this study were to (i) identify the species of Botryosphaeriaceae and Diaporthe associated with the English walnut disease based on molecular and morphological methods, (ii) clarify the geographic distribution of these pathogens, and (iii) determine pathogenicity of various fungal species or isolates and compare the tolerance of several English walnut cultivars to these fungi.

\section{Materials and Methods}

Collections of fungal isolates. Isolates used in this study were collected from English walnut trees in different counties of California from 1999 to 2011. Isolations were made from diseased stems, diseased shoots and twigs, and decayed fruit, as well as from pycnidia formed on the diseased tissues of English walnut, showing typical morphology of Botryosphaeriaceae or Diaporthe fungi. Affected tissues were surface disinfested with household bleach (Clorox Professional Product Company) at $10 \%$ (vol/vol) in sterile water for $3 \mathrm{~min}$. Bark tissues ( 3 to 5 by 2 to $5 \mathrm{~mm}$ ) were cut with a sterile scalpel and placed in petri dishes containing $2 \%$ potato dextrose agar (PDA; $20 \mathrm{~g}$ of potato dextrose agar and 1,000 $\mathrm{ml}$ of water; Microtech Scientific) acidified with lactic acid $(2.5 \mathrm{ml}$ of $25 \%$ [vol/vol] per liter of medium; APDA) to minimize bacterial growth. When fungal fruiting structures formed on the diseased tissue, the fruiting structures were removed using a sterile transfer needle and cultured in petri dishes on APDA. Petri dishes were incubated at $25 \pm 3^{\circ} \mathrm{C}$ for 2 to 7 days until fungal colonies were large enough to be examined. To obtain pure cultures, single hyphal tips from the colonies with typical growth characteristics of Botryosphaeriaceae or Diaporthe spp. were transferred to fresh PDA and incubated as described above. These isolates are maintained in the culture collection of the Department of Plant Pathology at the University of California, Davis (Kearney Agricultural Research and Extension Center in Parlier). In addition to isolates from English walnut in California, some other isolates in our tree hosts which were isolated from almond, avocado, and pomegranate in California, as well as isolates from English walnut in Greece and Spain, were also used in this study.

DNA extraction, polymerase chain reaction amplification, and DNA sequencing. For DNA extraction, single-hyphal cultures were grown on $2 \%$ PDA for 7 to 10 days at $25 \pm 3{ }^{\circ} \mathrm{C}$ to obtain pure single-genotype cultures. Mycelium used for DNA extraction was scraped directly from the medium using a sterile scalpel. The total genomic DNA was extracted from pure culture mycelia using a FastDNA Kit (BIO 101, Inc.). The internal transcribed spacer (ITS) regions ITS1 and ITS2 and the 5.8S gene of the ribosomal DNA were amplified using primers ITS1 and ITS4 (68). Part of the translation elongation factor $1-\alpha($ TEF- $1 \alpha)$ gene was amplified using the primers EF1-728F and EF1-986R (10). A portion of the $\beta$-tubulin (BT) gene was amplified by the primers Bt2A and Bt2B (23). The polymerase chain reaction (PCR) of ITS, TEF- $1 \alpha$, and BT was conducted according to previous studies $(15,53)$. The PCR products were purified using an Ultra Clean PCR Clean-Up Kit (MO BIO Laboratories, Inc.).

The resulting amplicons were sequenced in both directions using the same primers that were used for PCRs. Sequence reactions were run by using an automated sequencer by the Division of Biological Sciences sequencing facility, University of California-Davis. The nucleotide sequences were read and edited using MEGA4 software (55). Sequences obtained in this study were deposited in GenBank.

Phylogenetic analyses. The ITS, TEF- $1 \alpha$, and BT sequence of the strains isolated in this study were subjected to BLAST search using the National Center for Biotechnology Information (National
Center for Biotechnology Information [NCBI]; http://www.ncbi. nlm.nih.gov) nucleotide database to obtain preliminary identifications. Sequences of the type specimen isolates or strains for closely related Botryosphaeriaceae and Diaporthe spp. were obtained from GenBank (http://www.ncbi.nlm.nih.gov) to compile datasets for phylogenetic analyses. The sequences for each of the three gene regions were aligned using the online interface of MAFFT v. 5.667 (29), with the iterative refinement method (FFTNS-i settings). The sequence alignments were edited manually in MEGA4 (55). The sequence alignments for each of the datasets were deposited in TreeBASE (http://treebase.org/treebase-web/).

Maximum-likelihood (ML) phylogenetic analyses were conducted for each of the ITS, TEF- $1 \alpha$, and BT datasets. The best models of nucleotide substitution were established with Modeltest 3.7 (46). The ML analyses were conducted with PhyML 3.0 (25). For the ML analyses, additional ML parameters in PhyML included the retention of the maximum number of 1,000 trees and the determination of nodal support by nonparametric bootstrapping with 1,000 replicates. MEGA4 was used to construct consensus trees (55).

Culture and conidia morphological characterization. In order to characterize species of Botryosphaeriaceae and Diaporthe using the morphological characteristics and depending on the amount of isolates identified by the phylogenetic analyses, one to six representative isolates of each species were selected to study their culture and conidia characteristics. A 7-mm plug of a colony for each selected isolate was removed from these cultures and transferred to the center of $90-\mathrm{mm}$ petri dishes containing 2\% PDA. These cultures were grown at different incubation temperatures of 0 to $40^{\circ} \mathrm{C}$ at $5^{\circ} \mathrm{C}$ intervals for 2 to 4 days. Five replicate plates of each isolate were used at each temperature. The plates were incubated in the dark and two measurements of colony diameter, at right angles to each other, were taken daily until the fastest-growing culture had covered the plate, and the averages were then calculated for each of the nine temperatures. The experiment was repeated once. Colony morphological characteristics were observed and colony color was determined using the color charts of Rayner (47).

To study conidial morphology of the selected representative isolates, pycnidia formation was induced by growing isolates on a $2 \%$ agar medium with pistachio leaves (pistachio leaves were autoclaved at $120^{\circ} \mathrm{C}$ for $20 \mathrm{~min}$ and then placed into petri dishes containing a $2 \%$ agar medium (agar; $10 \mathrm{~g}$ of agar and $500 \mathrm{ml}$ of water; Microtech Scientific) that were incubated at $25 \pm 3^{\circ} \mathrm{C}$ for 15 days. Pycnidia-containing conidia were mounted in sterile water and squeezed on glass slides, and the length and width of 50 conidia for each isolate were measured at a magnification of $\times 1,000$ with a compound microscope (Zeiss Microscope System Standard 16; Carl Zeiss Ltd.). Average (mean), standard deviation (std. dev.), minimum ( $\min )$, and maximum $(\max )$ measurements were made and are presented as (min-) (average - std. dev.) - (average + std. dev.) (-max) for each isolate. Conidial shape, color, and the presence of septa were also recorded.

Inoculation of walnut branches and hulls with mycelium plugs. To test pathogenicity, one to three isolates of each identified species of Botryosphaeriaceae and Diaporthe from English walnut in California were selected for the field inoculation tests. Three cultivars ('Chandler', 'Tulare', and 'Vina') of J. regia were selected. Pathogenicity tests were conducted by inoculating 2-yearold branches and the current hulls of the fruit. Inoculations were conducted by using a 7-mm mycelium PDA plug from a 7-day-old culture. Wounding of the bark and hulls was created with a 7-mm cork borer and placing an agar plug bearing mycelia, upper surface down, into the fresh wound. Five 2-year-old branches or hulls of five fruit per isolate were inoculated. Five additional branches or hulls of each of the three cultivars were wounded and inoculated with a sterile $2 \%$ PDA plug and served as negative controls. Two experiments (the first in July and the second in August 2012) were conducted using the same methodology. Infection data were recorded 3 weeks after inoculation by measuring length of branch canker and fruit blight. 
Effect of inoculation method on infection of walnut. To test the effect of inoculation method on infection of English walnut, branches and fruit on walnut trees were inoculated with either a mycelium plug or a conidial suspension. Isolates in the species which were dominant in distribution or most pathogenic were selected. The mycelium plug inoculation method was performed as described above. For the conidial suspension inoculation, a suspension of $1.0 \times 10^{6}$ conidia/ml was used. Pathogenicity tests were conducted by inoculating five 2-year-old branches or hulls of five fruits per isolate for each inoculation method. Five additional branches or hulls of each of the three cultivars were inoculated with a sterile $2 \%$ PDA plug or water and served as negative controls. All the inoculations were conducted on Chandler, Tulare, and Vina walnut. Two inoculation experiments (the first in July and the second in August) were conducted. Three weeks after each inoculation method, length of developed cankers and blight of fruits were recorded.
Statistical analyses. Results of experiments of this study were analyzed with SAS (51) using the PROC general liner model. Analysis of variance was performed on the data and treatment means were compared using Tukey's least significant difference test at $P=0.05$.

\section{Results}

Collection of fungal isolates. In California, 159 fungal isolates from English walnut showing typical morphology of Botryosphaeriaceae or Diaporthe fungi were collected from 13 counties. These counties included Butte, Colusa, Fresno, Glenn, Kings, Merced, San Benito, Stanislaus, Sutter, Tulare, Ventura, Yolo, and Yuba (Table 1; Fig. 1). In California, in addition to English walnut, 19 more isolates with typical characteristics of family Botryosphaeriaceae were collected: 15 from pomegranate, 2 from almond, 1 from Umbellularia californica (California Bay Laurel), and 1 from avocado. Furthermore, nine and two isolates of

Table 1. Isolates sequenced and used for phylogenetic study and pathogenicity tests in this study

\begin{tabular}{|c|c|c|c|c|c|c|c|c|}
\hline \multirow[b]{2}{*}{ Identity } & \multirow[b]{2}{*}{ Type $^{\mathrm{v}}$} & \multirow{2}{*}{$\frac{\text { Number }}{\text { Isolate }}$} & \multirow[b]{2}{*}{ Host } & \multirow[b]{2}{*}{ Locationw } & \multirow[b]{2}{*}{ Date $^{x}$} & \multicolumn{3}{|c|}{ GenBank accession number ${ }^{\mathrm{u}}$} \\
\hline & & & & & & ITS & TEF-1 $\alpha$ & BT2 \\
\hline \multicolumn{9}{|l|}{ Botryosphaeriaceae } \\
\hline Botryosphaeria dothidea & AAA & $2 \mathrm{E} 55^{\mathrm{y}, \mathrm{z}}$ & Juglans regia & Orland, Glenn, CA & $4 / 4 / 2000$ & KF778783 & KF778973 & KF778878 \\
\hline B. dothidea & AAA & $2 \mathrm{~K} 23$ & J. regia & California & $1 / 10 / 2010$ & KF778784 & KF778974 & KF778879 \\
\hline B. dothidea & BAA & $2 \mathrm{D} 20^{\mathrm{y}, \mathrm{z}}$ & J. regia & Chico, Butte, CA & $3 / 2 / 2009$ & KF778785 & KF778975 & KF778880 \\
\hline B. dothidea & BAA & $6 \mathrm{I} 19^{y}$ & J. regia & Yuba, CA & $9 / 16 / 2011$ & KF778786 & KF778976 & KF778881 \\
\hline B. dothidea & CBA & $5 \mathrm{~A} 02$ & J. regia & Greece & $7 / 2 / 2010$ & KF778787 & KF778977 & KF778882 \\
\hline B. dothidea & CBA & $5 \mathrm{~A} 03^{\mathrm{z}}$ & J. regia & Greece & $7 / 2 / 2010$ & KF778788 & KF778978 & KF778883 \\
\hline Diplodia mutila & AAA & 4D33 & Persea americana & Ventura, CA & $6 / 15 / 2004$ & KF778789 & KF778979 & KF778884 \\
\hline D. mutila & AAA & $5 B 64$ & J. regia & Cordoba, Spain & $8 / 12 / 2010$ & KF778790 & KF778980 & KF779885 \\
\hline D. mutila & AAA & 6B99y,z & J. regia & Yolo, CA & $5 / 31 / 2011$ & KF778791 & KF778981 & KF778886 \\
\hline D. mutila & AAA & 6F64 & Punica granatum & Tulare, CA & $7 / 16 / 2011$ & KF778792 & KF778982 & KF778887 \\
\hline D. mutila & AAA & $6 \mathrm{~F} 65^{\mathrm{y}, \mathrm{z}}$ & P. granatum & Tulare, CA & $7 / 16 / 2011$ & KF778793 & KF778983 & KF778888 \\
\hline D. mutila & AAA & 6F66 & P. granatum & Tulare, CA & $7 / 16 / 2011$ & KF778794 & KF778984 & KF778889 \\
\hline Diplodia seriata & AAA & $2 \mathrm{~K} 33$ & P. granatum & Parlier, Fresno. CA & $10 / 2 / 2009$ & KF778795 & KF778985 & KF778890 \\
\hline D. seriata & AAA & $3 \mathrm{H} 18^{\mathrm{y}, \mathrm{z}}$ & J. regia & Parlier, Fresno. CA & $1 / 15 / 2004$ & KF778796 & KF778986 & KF778891 \\
\hline D. seriata & AAA & $3 \mathrm{~K} 67$ & J. regia & Tulare, CA & $3 / 18 / 2010$ & KF778797 & KF778987 & KF778892 \\
\hline D. seriata & AAA & $3 \mathrm{~K} 69$ & J. regia & Tulare, CA & $3 / 18 / 2010$ & KF778798 & KF778988 & KF778893 \\
\hline D. seriata & AAA & $4 \mathrm{D} 23$ & J. regia & Merced, CA & $4 / 1220 / 05$ & KF778799 & KF778989 & KF778894 \\
\hline D. seriata & AAA & $5 \mathrm{C} 52$ & J. regia & Kings, CA & $9 / 20 / 2010$ & KF778800 & KF778990 & KF778895 \\
\hline D. seriata & AAA & $5 \mathrm{~F} 07$ & J. regia & Tulare, CA & $10 / 2 / 2010$ & KF778801 & KF778991 & KF778896 \\
\hline D. seriata & AAA & $5 \mathrm{~F} 12$ & J. regia & Hollister, CA & $9 / 22 / 2010$ & KF778802 & KF778992 & KF778897 \\
\hline D. seriata & $\mathrm{BBB}$ & $3 \mathrm{~K} 70^{\mathrm{z}}$ & J. regia & Tulare, CA & $3 / 18 / 2010$ & KF778803 & KF778993 & KF778898 \\
\hline D. seriata & $\mathrm{BCB}$ & $5 \mathrm{E} 99$ & J. regia & California & $10 / 7 / 2010$ & KF778804 & KF778994 & KF778899 \\
\hline D. seriata & $\mathrm{BCB}$ & $5 \mathrm{~F} 10$ & J. regia & Hollister, CA & $9 / 22 / 2010$ & KF778805 & KF778995 & KF778900 \\
\hline D. seriata & $\mathrm{BCB}$ & $5 \mathrm{~F} 11^{\mathrm{y}, \mathrm{z}}$ & J. regia & Hollister, CA & $9 / 22 / 2010$ & KF778806 & KF778996 & KF778901 \\
\hline D. seriata & $\mathrm{BCB}$ & $5 \mathrm{~F} 13$ & J. regia & Hollister, CA & $9 / 22 / 2010$ & KF778807 & KF778997 & KF778902 \\
\hline Dothiorella iberica & AAA & $5 \mathrm{G} 97^{\mathrm{y}, \mathrm{z}}$ & J. regia & Davis, Yolo, CA & $12 / 13 / 2010$ & KF778808 & KF778998 & KF778903 \\
\hline Lasiodiplodia citricola & AAA & $6 \mathrm{I} 34^{\mathrm{y}, \mathrm{z}}$ & J. regia & Stanislaus, CA & $10 / 6 / 2011$ & KF778809 & KF778999 & KF778904 \\
\hline L. citricola & AAA & $6 \mathrm{I} 35^{\mathrm{y}, \mathrm{z}}$ & J. regia & Stanislaus, CA & $10 / 6 / 2011$ & KF778810 & KF779000 & KF778905 \\
\hline Neofuscicoccum mediterraneum & AAA & $1 \mathrm{H} 96$ & J. regia & Selma, Fresno, CA & $9 / 15 / 2006$ & KF778811 & KF779001 & KF778906 \\
\hline N. mediterraneum & AAA & 1L86 & J. regia & Stanislaus, CA & $8 / 27 / 2004$ & KF778812 & KF779002 & KF778907 \\
\hline N. mediterraneum & AAA & 4D13 & J. regia & Parlier, Fresno. CA & 11/18/1999 & KF778813 & KF779003 & KF778908 \\
\hline N. mediterraneum & AAA & $4 K 69^{z}$ & J. regia & Stanislaus, CA & $9 / 21 / 2004$ & KF778814 & KF779004 & KF778909 \\
\hline N. mediterraneum & AAA & 5D03 & J. regia & Yuba or Sutter, CA & $5 / 6 / 2010$ & KF778815 & KF779005 & KF778910 \\
\hline N. mediterraneum & AAA & $6 \mathrm{~F} 33$ & J. regia & Tulare, CA & $7 / 6 / 2011$ & KF778816 & KF779006 & KF778911 \\
\hline N. mediterraneum & AAA & $6 \mathrm{~F} 35$ & J. regia & Tulare, CA & $7 / 6 / 2011$ & KF778817 & KF779007 & KF778912 \\
\hline N. mediterraneum & BAB & 1L85 & J. regia & Butte, CA & $11 / 4 / 2005$ & KF778818 & KF779008 & KF778913 \\
\hline N. mediterraneum & BAB & $3 \mathrm{~K} 72$ & J. regia & Sutter, CA & $3 / 24 / 2010$ & KF778819 & KF779009 & KF778914 \\
\hline N. mediterraneum & BAB & $3 \mathrm{~K} 77$ & J. regia & Stanislaus, CA & $3 / 30 / 2010$ & KF778820 & KF779010 & KF778915 \\
\hline N. mediterraneum & $\mathrm{BAB}$ & $4 C 52$ & J. regia & Tulare, CA & $9 / 10 / 2003$ & KF778821 & KF779011 & KF778916 \\
\hline N. mediterraneum & BAB & 4D04 & J. regia & Durham, Butte, CA & $11 / 4 / 2005$ & KF778822 & KF779012 & KF778917 \\
\hline N. mediterraneum & $\mathrm{BAB}$ & $5 \mathrm{~A} 05$ & J. regia & Yuba, CA & $7 / 2 / 2010$ & KF778823 & KF779013 & KF778918 \\
\hline N. mediterraneum & BAB & $5 \mathrm{C} 88$ & J. regia & Yuba or Sutter, CA & $5 / 6 / 2010$ & KF778824 & KF779014 & KF778919 \\
\hline N. mediterraneum & BAB & $5 \mathrm{C} 92$ & J. regia & Yuba, CA & $6 / 14 / 2010$ & KF778825 & KF779015 & KF778920 \\
\hline N. mediterraneum & BAB & 5 G96 & J. regia & Davis, Yolo, CA & $12 / 13 / 2010$ & KF778926 & KF779016 & KF778921 \\
\hline N. mediterraneum & $\mathrm{BAB}$ & $5 \mathrm{G} 100$ & J. regia & Davis, Yolo, CA & $12 / 13 / 2010$ & KF778827 & KF779017 & KF778922 \\
\hline
\end{tabular}

\footnotetext{
u ITS = internal transcribed spacer, TEF-1- $\alpha=$ translation elongation factor $1-\alpha$, and BT2 = $\beta$-tubulin- 2 gene regions.

${ }^{v}$ Genotype within each identified species, determined by sequence of ITS, TEF-1 $\alpha$, and BT2 gene regions.

${ }^{\mathrm{w}}$ Hollister $=$ Hollister, San Benito, CA; Santa Nella = Santa Nella, Merced, CA; and Maxwell = Maxwell, Colusa, CA.

${ }^{x}$ Collection date: month/day/year.

y Isolates used in field pathogenicity tests on J. regia in this study.

${ }^{\mathrm{z}}$ Isolates used for colony growth, culture morphology, and conidia morphology in this study.
} 
Botryosphaeriaceae were isolated from English walnut in Spain and Greece, respectively.

Phylogenetic analyses. Isolates which represented different genotypes determined by the ITS, TEF- $1 \alpha$, and BT gene regions and covering all the hosts and sampled regions (counties) were selected for phylogenetic analyses (Table 1), and sequences of these selected isolates were deposited in GenBank (Table 1). All the isolates can be separated into two groups by the BLAST searches using the NCBI nucleotide database: the family Botryosphaeriaceae and genus Diaporthe. The phylogenetic analyses for the sequences of isolates in this study (Table 1) and sequences obtained from GenBank (Table 2) were conducted within Botryosphaeriaceae and Diaporthe, respectively.

Phylogenetic analyses of species of Botryosphaeriaceae. For the species of Botryosphaeriaceae, PCR of isolates resulted in amplicons of approximately $550 \mathrm{bp}$ for the ITS, $300 \mathrm{bp}$ for the TEF- $1 \alpha$, and 450 bp for the BT gene regions. The aligned sequences of each dataset of ITS (83 taxa, 571 characters), TEF-1 $\alpha$
(83 taxa, 354 characters), and BT (71 taxa, 421 characters) gene regions were deposited in TreeBASE (number 14888). For ML analyses, model test analysis recommended a TIM+G model (Lset base $=[0.2213,0.2830,0.2554]$; number of substitution rate categories $[\mathrm{Nst}]=6$; rate matrix $=[1.0000,3.9000,2.0980,2.0980$, 7.0404]; rates $=\gamma$; shape $=0.1938]$ for the ITS gene region, a $\mathrm{TVM}+\mathrm{G}$ model $[$ Lset base $=[0.1706,0.3223,0.2695] ;$ Nst $=6$; rate matrix $=[2.4163,5.7914,1.5365,1.2889,5.7914] ;$ rates $=\gamma$; shape $=0.8288]$ for the TEF- $1 \alpha$ gene region, and a TrN+G model $[$ Lset base $=[0.1974,0.3288,0.2506] ;$ Nst $=6$; rate matrix $=$ $[1.0000,1.7842,1.0000,1.0000,5.3879] ;$ rates $=\gamma$; shape $=$ $0.3339]$ for the BT gene regions.

Phylogenetic analyses based on three gene regions were unable to resolve the order of divergence of the genera within the family Botryosphaeriaceae; however, each genus is strongly supported (Figs. 2-4). The only exceptions include the unsupported position of Dothiorella spp. which clustered among species of Neofusicoccum in the ITS analysis (Fig. 2). The combined analysis (results

Table 1. (continued from preceding page)

\begin{tabular}{|c|c|c|c|c|c|c|c|c|}
\hline \multirow[b]{2}{*}{ Identity } & \multirow[b]{2}{*}{ Type $^{\mathbf{v}}$} & \multirow{2}{*}{$\begin{array}{c}\text { Number } \\
\text { Isolate }\end{array}$} & \multirow[b]{2}{*}{ Host } & \multirow[b]{2}{*}{ Location $^{w}$} & \multirow[b]{2}{*}{ Date $^{x}$} & \multicolumn{3}{|c|}{ GenBank accession numberu } \\
\hline & & & & & & ITS & TEF-1 $\alpha$ & BT2 \\
\hline N. mediterraneum & $\mathrm{BAB}$ & $5 \mathrm{H} 01$ & J. regia & Fresno, CA & $1 / 15 / 2000$ & KF778828 & KF779018 & KF778923 \\
\hline N. mediterraneum & BAB & $5 \mathrm{H} 53^{\mathrm{y}, \mathrm{z}}$ & J. regia & Colusa, CA & $12 / 13 / 2010$ & KF778829 & KF779019 & KF778924 \\
\hline N. mediterraneum & $\mathrm{BAB}$ & $5 \mathrm{H} 91$ & J. regia & Santa Nella, CA & $1 / 31 / 2011$ & KF778830 & KF779020 & KF778925 \\
\hline N. mediterraneum & BAB & $5 \mathrm{~L} 44$ & J. regia & Colusa, CA & $2 / 24 / 2011$ & KF778831 & KF779021 & KF778926 \\
\hline N. mediterraneum & BAB & $6 \mathrm{~F} 30$ & P. granatum & Tulare, CA & $7 / 6 / 2011$ & KF778832 & KF779022 & KF778927 \\
\hline N. mediterraneum & $\mathrm{BAB}$ & $6 \mathrm{~F} 62$ & P. granatum & Tulare, CA & $7 / 16 / 2011$ & KF778833 & KF779023 & KF778928 \\
\hline N. mediterraneum & BAB & $6 \mathrm{I} 24$ & J. regia & Stanislaus, CA & $10 / 6 / 2011$ & KF778834 & KF779024 & KF778929 \\
\hline N. mediterraneum & BAB & $6 \mathrm{I} 32$ & J. regia & Stanislaus, CA & $10 / 6 / 2011$ & KF778835 & KF779025 & KF778930 \\
\hline N. mediterraneum & CAA & $2 \mathrm{E} 54$ & J. regia & Orland, CA & $4 / 4 / 2000$ & KF778836 & KF779026 & KF778931 \\
\hline N. mediterraneum & CAA & $3 \mathrm{~K} 78$ & J. regia & Stanislaus, CA & $3 / 30 / 2010$ & KF778837 & KF779027 & KF778932 \\
\hline N. mediterraneum & CAA & $3 \mathrm{~K} 80$ & J. regia & Stanislaus, CA & $3 / 30 / 2010$ & KF778838 & KF779028 & KF778933 \\
\hline N. mediterraneum & CAA & $4 \mathrm{C} 26$ & J. regia & Tulare, CA & $9 / 10 / 2003$ & KF778839 & KF779029 & KF778934 \\
\hline N. mediterraneum & CAA & 4L59 & J. regia & Winters, Yolo, CA & $6 / 10 / 2010$ & KF778840 & KF779030 & KF778935 \\
\hline N. mediterraneum & CAA & $4 \mathrm{~L} 77$ & J. regia & Winters, Yolo, CA & $6 / 24 / 2010$ & KF778841 & KF779031 & KF778936 \\
\hline N. mediterraneum & CAA & $5 \mathrm{H} 09^{\mathrm{y}, \mathrm{z}}$ & J. regia & Colusa, CA & $12 / 13 / 2010$ & KF778842 & KF779032 & KF778937 \\
\hline N. mediterraneum & DAB & $4 \mathrm{C} 06$ & J. regia & Colusa, CA & $7 / 23 / 2004$ & KF778843 & KF779033 & KF778938 \\
\hline N. mediterraneum & DAB & $5 \mathrm{C} 86$ & J. regia & Yuba, CA & $7 / 1 / 2010$ & KF778844 & KF779034 & KF778939 \\
\hline N. mediterraneum & $\mathrm{DAB}$ & $5 \mathrm{C} 87^{y, z}$ & J. regia & Yuba, CA & $7 / 1 / 2010$ & KF778845 & KF779035 & KF778940 \\
\hline N. mediterraneum & $\mathrm{DAB}$ & $5 \mathrm{H} 89$ & J. regia & Maxwell, CA & $1 / 31 / 2011$ & KF778846 & KF779036 & KF778941 \\
\hline N. mediterraneum & DAB & $6 \mathrm{~F} 52$ & P. granatum & Tulare, CA & $7 / 16 / 2011$ & KF778847 & KF779037 & KF778942 \\
\hline N. mediterraneum & DAB & $6 \mathrm{I} 27$ & J. regia & Stanislaus, CA & $10 / 6 / 2011$ & KF778848 & KF779038 & KF778943 \\
\hline N. mediterraneum & DAB & $6 \mathrm{I} 29$ & J. regia & Stanislaus, CA & $10 / 6 / 2011$ & KF778849 & KF779039 & KF778944 \\
\hline \multirow[t]{2}{*}{ N. nonquaesitum } & AAA & $4 \mathrm{E} 64$ & Umbellularia & & & & & \\
\hline & & & californica & Colusa, CA & $4 / 1 / 2004$ & KF778850 & KF779040 & KF778945 \\
\hline N. nonquaesitum & AAA & $4 \mathrm{~L} 78^{\mathrm{z}}$ & J. regia & Sutter, CA & $6 / 24 / 2010$ & KF778851 & KF779041 & KF778946 \\
\hline N. nonquaesitum & AAA & $5 \mathrm{~A} 04^{\mathrm{y}, \mathrm{z}}$ & J. regia & Yuba, CA & $7 / 2 / 2010$ & KF778852 & KF779042 & KF778947 \\
\hline N. nonquaesitum & AAA & $5 \mathrm{H} 50$ & J. regia & Colusa, CA & $12 / 13 / 2010$ & KF778853 & KF779043 & KF778948 \\
\hline Neofusicoccum parvum & AAA & $1 \mathrm{L83}{ }^{\mathrm{y}}$ & J. regia & Butte, CA & $11 / 4 / 2005$ & KF778854 & KF779044 & KF778949 \\
\hline N. parvum & AAA & $1 \mathrm{~L} 87^{\mathrm{y}, \mathrm{z}}$ & J. regia & Butte, CA & $11 / 4 / 2005$ & KF778855 & KF779045 & KF778950 \\
\hline N. parvum & AAA & $2 \mathrm{E} 43^{\mathrm{y}}$ & J. regia & Durham, Butte, CA & $11 / 4 / 2005$ & KF778856 & KF779046 & KF778951 \\
\hline N. parvum & AAA & 4D10 & J. regia & Durham, Butte, CA & $11 / 4 / 2005$ & KF778857 & KF779047 & KF778952 \\
\hline N. parvum & AAA & $5 \mathrm{~B} 61$ & J. regia & Spain & $8 / 12 / 2010$ & KF778858 & KF779048 & KF778953 \\
\hline N. parvum & AAA & $5 \mathrm{~B} 63$ & J. regia & Spain & $8 / 12 / 2010$ & KF778859 & KF779049 & KF778954 \\
\hline N. parvum & AAA & $5 \mathrm{~B} 65$ & J. regia & Spain & $8 / 12 / 2010$ & KF778860 & KF779050 & KF778955 \\
\hline N. parvum & $\mathrm{BBB}$ & $5 \mathrm{~B} 60^{\mathrm{z}}$ & J. regia & Spain & $8 / 12 / 2010$ & KF778861 & KF779051 & KF778956 \\
\hline N. parvum & $\mathrm{BBB}$ & $6 \mathrm{~B} 97^{\mathrm{z}}$ & J. regia & Yolo, CA & $5 / 31 / 2011$ & KF778862 & KF779052 & KF778957 \\
\hline N. parvum & $\mathrm{BBB}$ & $5 B 602$ & J. regia & Spain & $8 / 12 / 2010$ & KF778863 & KF779053 & KF778958 \\
\hline N. parvum & $\mathrm{BBC}$ & $5 C 95^{z}$ & J. regia & Stanislaus, CA & $6 / 17 / 2010$ & KF778864 & KF779054 & KF778959 \\
\hline N. parvum & CAA & $2 \mathrm{D} 18^{\mathrm{z}}$ & J. regia & Spain & $5 / 26 / 2009$ & KF778865 & KF779055 & KF778960 \\
\hline N. parvum & CAA & $5 \mathrm{~B} 67$ & J. regia & Spain & $8 / 12 / 2010$ & KF778866 & KF779056 & KF778961 \\
\hline N. parvum & $\mathrm{DBC}$ & $5 \mathrm{~B} 62^{\mathrm{z}}$ & J. regia & Spain & $8 / 12 / 2010$ & KF778867 & KF779057 & KF778962 \\
\hline N. vitifusiforme & AAA & $5 \mathrm{H} 02^{\mathrm{y}, \mathrm{z}}$ & J. regia & Fresno, CA & $5 / 11 / 2001$ & KF778868 & KF779058 & KF778963 \\
\hline N. vitifusiforme & AAA & $5 \mathrm{H} 022^{\mathrm{z}}$ & J. regia & Fresno, CA & $5 / 11 / 2001$ & KF778869 & KF779059 & KF778964 \\
\hline Neoscytalidium dimidiatum & AAA & $2 \mathrm{D} 57^{\mathrm{y}, \mathrm{z}}$ & J. regia & Kings, CA & $9 / 16 / 2009$ & KF778870 & KF779060 & KF778965 \\
\hline \multicolumn{9}{|l|}{ Diaporthe } \\
\hline Diaporthe neotheicola & AAA & $6 \mathrm{I} 30^{\mathrm{y}, \mathrm{z}}$ & J. regia & Stanislaus, CA & $10 / 6 / 2011$ & KF778871 & KF779061 & KF778966 \\
\hline D. rhusicola & AAA & $6 \mathrm{I} 14^{\mathrm{z}}$ & Prunus dulcis & Kings, CA & $9 / 12 / 2011$ & KF778872 & KF779062 & KF778967 \\
\hline D. rhusicola & AAA & $6 \mathrm{I} 15$ & P. dulcis & Kings, CA & $9 / 12 / 2011$ & KF778873 & KF779063 & KF778968 \\
\hline D. rhusicola & AAA & $6 \mathrm{I} 31$ & J. regia & Stanislaus, CA & $10 / 6 / 2011$ & KF778874 & KF779064 & KF778969 \\
\hline D. rhusicola & AAA & $6 \mathrm{I} 43^{\mathrm{z}}$ & J. regia & Stanislaus, CA & $10 / 6 / 2011$ & KF778875 & KF779065 & KF778970 \\
\hline D. rhusicola & AAA & $6 \mathrm{I} 44^{y}$ & J. regia & Stanislaus, CA & $10 / 6 / 2011$ & KF778876 & KF779066 & KF778971 \\
\hline D. rhusicola & AAA & $6 \mathrm{I} 54$ & J. regia & Stanislaus, CA & $10 / 20 / 2011$ & KF778877 & KF779067 & KF778972 \\
\hline
\end{tabular}


not shown) was concordant with the three individual datasets. Isolates in this study consisted of six genera within the family Botryosphaeriaceae, which included Diplodia, Dothiorella, FusicoccumBotryosphaeria, Lasiodiplodia, Neofusicoccum, and Neoscytalidium.

In the Diplodia phylogenetic lineage, isolates in this study clustered in to two phylogenetic groups, which represented two species, Diplodia mutila (Figs. 2-4, BS $=100,100$, and 89\% for ITS, TEF- $1 \alpha$, and BT, respectively) and D. seriata. Only one isolate in this study clustered in the phylogenetic lineage of Dothiorella, which was identified as Dothiorella iberica (Figs. 2-4, BS $=95$, 99, and $70 \%$ for ITS, TEF- $1 \alpha$, and BT, respectively). In the Fusicoccum-Botryosphaeria phylogenetic lineage, isolates recovered in this study were identified as Botryosphaeria dothidea (Figs. 2-4). Two isolates from California grouped in the Lasiodiplodia phylogenetic lineage and were identified as L. citricola, which was supported by ITS and TEF- $1 \alpha$ gene analyses (Figs. 2 and 3, BS = 74, 96, and $91 \%$ for ITS, TEF- $1 \alpha$, and BT, respectively; BT gene sequences were not available for the ex-type specimens of $L$. citricola). Isolates that clustered in the Neofusicoccum phylogenetic lineage represented four species, which include $N$. mediterraneum, $N$. nonquaesitum, $N$. parvum, and $N$. vitifusiforme. For the isolates in the Neofusicoccum lineage which clustered in the $N$. mediterraneum phylogenetic group, several phylogenetic subgroups existed in ITS gene analyses, which were supported by high bootstrap values (Fig. 2, BS $=77,72$, and 93\%, respectively). In contrast, only one phylogenetic subgroup in the TEF- $1 \alpha$ gene analyses (Fig. 3) and two phylogenetic subgroups in the BT gene analyses (Fig. 4), all with low bootstrap values (BS $<70 \%$ ), existed. Because these multiple phylogenetic subgroups by ITS gene analysis were not supported by the TEF- $1 \alpha$ or BT genes analyses, indicating that these reflect intraspecific sequence differences rather than interspecific variation, all of these isolates were considered as $N$. mediterraneum. The remaining isolates of Neofusicoccum in this study were identified as $N$. nonquaesitum, $N$. parvum, and $N$. vitifusiforme, which were all supported by the phylogenetic analyses of the three gene regions (Figs. 2-4; BT is not available for the ex-type specimens of $N$. vitifusiforme). One isolate in this study clustered in the Neoscytalidium phylogenetic lineage and was identified as Neoscytalidium dimidiatum by the ITS and TEF- $1 \alpha$ gene regions (Figs. 2 and 3; BT gene sequence is not available for the ex-type specimen of $N$. dimidiatum).

Phylogenetic analyses of species of Diaporthe. For the species of Diaporthe, because the BT gene sequences for most isolates of Diaporthe are not available in the GenBank database, only the analyses of ITS and TEF- $1 \alpha$ gene regions were conducted in this study. PCR of isolates resulted in amplicons of approximately 550 bp for the ITS and $350 \mathrm{bp}$ for the TEF- $1 \alpha$ gene regions. For ML analyses, model test analysis recommended a $\operatorname{TrNef}+\mathrm{I}+\mathrm{G}$ model $($ Lset base $=$ equal; $\mathrm{Nst}=6$; rate matrix $=[1.0000,2.2035,1.0000$, $1.0000,5.3181]$; rates $=\gamma$; shape $=0.4725)$ for the ITS gene region

Table 2. Isolates and sequences from other studies used in phylogenetic analyses for this study

\begin{tabular}{|c|c|c|c|c|c|c|c|c|c|}
\hline \multirow[b]{2}{*}{ Species } & \multicolumn{2}{|c|}{ Number ${ }^{y}$} & \multirow[b]{2}{*}{ Host } & \multirow[b]{2}{*}{ Location } & \multirow[b]{2}{*}{ Collector } & \multicolumn{3}{|c|}{ GenBank accession number ${ }^{\mathrm{Z}}$} & \multirow[b]{2}{*}{ Refs } \\
\hline & Isolate & Other & & & & ITS & TEF-1 $\alpha$ & BT2 & \\
\hline \multicolumn{10}{|c|}{ Botryosphaeriaceae analyses } \\
\hline $\begin{array}{l}\text { Botryosphaeria } \\
\text { dothidea }\end{array}$ & CMW8000 & & Prunus sp. & $\begin{array}{l}\text { Crocifisso, } \\
\text { Switzerland }\end{array}$ & B. Slippers & AY236949 & AY236898 & AY236927 & 53 \\
\hline B. dothidea & CMW7780 & & $\begin{array}{l}\text { Fraxinus } \\
\text { excelsior }\end{array}$ & $\begin{array}{l}\text { Molinizza, } \\
\text { Switzerland }\end{array}$ & B. Slippers & AY236947 & AY236896 & AY236925 & 53 \\
\hline Diplodia cupressi & CBS $168.87^{\mathrm{T}}$ & & $\begin{array}{l}\text { Cupressus } \\
\text { sempervirens }\end{array}$ & Bet Dagan, Israel & Z. Solel & DQ458893 & DQ458878 & DQ458861 & 6 \\
\hline D. cupressi & CBS 261.85 & & C. sempervirens & Bet Dagan, Israel & Z. Solel & DQ458894 & DQ458879 & DQ458862 & 6 \\
\hline D. mutila & CBS $112553^{\mathrm{T}}$ & & Vitis vinifera & $\begin{array}{l}\text { Montemor-o- } \\
\text { Novo, Portugal }\end{array}$ & A. J. L. Phillips & AY259093 & AY573219 & DQ458850 & 5,30 \\
\hline D. mutila & CBS 230.30 & & $\begin{array}{l}\text { Phoenix } \\
\text { dactylifera }\end{array}$ & California, USA & L. L. Huillier & DQ458886 & DQ458869 & DQ458849 & 5,30 \\
\hline D. scrobiculata & CBS 113424 & & Pinus greggii & Mexico & M. J. Wingfield & DQ458900 & DQ458885 & DQ458868 & 6 \\
\hline D. scrobiculata & CBS 109944 & & P. greggii & Mexico & M. J. Wingfield & DQ458899 & DQ458884 & DQ458867 & 6 \\
\hline D. seriata & CBS $112555^{\mathrm{T}}$ & & Vitis vinifera & $\begin{array}{l}\text { Montemor-o- } \\
\text { Novo, Portugal }\end{array}$ & A. J. L. Phillips & AY259094 & AY573220 & DQ458856 & 6,45 \\
\hline D. seriata & CBS 119049 & & Vitis sp. & Italy & L. Mugnai & DQ458889 & DQ458874 & DQ458857 & 6,45 \\
\hline Dothiorella iberica & CBS $115041^{\mathrm{T}}$ & & Quercus ilex & Spain & J. Luque & AY573202 & AY573222 & EU673096 & 30,44 \\
\hline D. iberica & CBS 113188 & & Q. suber & Spain & M. E. Sanchez & AY573198 & EU673278 & EU673097 & 30,44 \\
\hline D. sarmentorum & IMI $63581 b^{\mathrm{T}}$ & & Ulmus sp. & $\begin{array}{l}\text { Warwickshire, } \\
\text { England }\end{array}$ & E. A. Ellis & AY573212 & AY573235 & EU673102 & 30,44 \\
\hline D. sarmentorum & CBS 115038 & & Malus pumila & Delft, Netherlands & A. J. L. Phillips & AY573206 & AY573223 & EU673101 & 30,44 \\
\hline $\begin{array}{l}\text { Fusicoccum } \\
\text { fabicercianum }\end{array}$ & CMW27094 ${ }^{\mathrm{T}}$ & CBS 127193 & Eucalyptus sp. & FuJian, China & M. J. Wingfield & HQ332197 & HQ332213 & KF779068 & 15 \\
\hline F. fabicercianum & CMW27121 & CBS 127194 & Eucalyptus sp. & FuJian, China & M. J. Wingfield & HQ332198 & HQ332214 & KF779069 & 15 \\
\hline F. ramosum & CMW26167 & CBS 122069 & $\begin{array}{l}\text { Eucalyptus } \\
\text { camaldulensis }\end{array}$ & $\begin{array}{l}\text { Bell Gorge, West- } \\
\text { ern Australia }\end{array}$ & T. I. Burgess & EU144055 & EU144070 & N/A & 35 \\
\hline $\begin{array}{r}\text { Guignardia } \\
\text { philoprina }\end{array}$ & CMW7063 & CBS 447 & $\begin{array}{l}\text { Terminalia } \\
\text { baccata }\end{array}$ & Netherlands & H. A. van der Aa & AY236956 & AY236905 & AY236934 & 53 \\
\hline $\begin{array}{l}\text { Lasiodiplodia } \\
\text { citricola }\end{array}$ & IRAN1522C ${ }^{\mathrm{T}}$ & CBS 124707 & Citrus sp. & Iran & $\begin{array}{l}\text { J. Abdollahzadeh \& } \\
\text { A. Javadi }\end{array}$ & GU945354 & GU945340 & N/A & 1 \\
\hline L. citricola & IRAN1521C & CBS 124706 & Citrus sp. & Iran & A. Shekari & GU945353 & GU945339 & N/A & 1 \\
\hline L. parva & CBS $456.78^{\mathrm{T}}$ & & $\begin{array}{l}\text { Manihot escu- } \\
\text { lenta field soil }\end{array}$ & Colombia & O. Rangel & EF622083 & EF622063 & N/A & 7 \\
\hline L. parva & CBS 494.78 & & $\begin{array}{l}\text { M. esculenta } \\
\text { field soil }\end{array}$ & Colombia & O. Rangel & EF622084 & EF622064 & EU673114 & 7 \\
\hline L. pseudotheobromae & CBS $116459^{\mathrm{T}}$ & & $\begin{array}{l}\text { Gmelina } \\
\text { arborea }\end{array}$ & Costa Rica & J. Carranza-Velásquez & EF622077 & EF622057 & EU673111 & 7 \\
\hline
\end{tabular}

${ }^{\mathrm{y}} \mathrm{CMW}=$ Culture collection of the Forestry and Agricultural Biotechnology Institute (FABI), University of Pretoria, Pretoria, South Africa; CBS $=$ the Centraalbureau voor Schimmelcultures, Utrecht, The Netherlands; IMI = CABI Bioscience, Egham, U.K.; IRAN = isolates from 1; PD = isolates from 28; STE-U = Department of Plant Pathology, University of Stellenbosch, South Africa; CPC = Culture collection of Pedro Crous, housed at CBS; $\mathrm{T}=$ isolates are ex-type or from samples that have been linked morphologically to type material of the species.

${ }^{\mathrm{z}}$ ITS $=$ internal transcribed spacer, TEF-1- $\alpha=$ translation elongation factor $1-\alpha, \mathrm{BT} 2=\beta$-tubulin-2 gene regions., and N/A = not available. 
and an HKY $+\mathrm{G}$ model (Lset base $=[0.2212,0.3438,0.1762]$; Nst $=2 ;$ transition $/$ transversion ratio $=2.8057$; rates $=\gamma ;$ shape $=$ 1.0599) for the TEF- $1 \alpha$ gene region.

The aligned sequences of each dataset of ITS (14 taxa, 627 characters) and TEF-1 $\alpha$ (13 taxa, 384 characters) gene regions were deposited in TreeBASE (number 14888). Phylogenetic analyses revealed that isolates in this study grouped into two phylogenetic groups of Diaporthe. One isolate was identified as Diaporthe neotheicola, which was conserved with the ex-type specimen isolates of D. neotheicola (Figs. 5 and 6, BS $=100$ and 73\% for ITS and TEF- $1 \alpha$, respectively). Six isolates were phylogenetically close to the ex-type specimen of $D$. rhusicola in the ITS phylogenetic analysis (Fig. 5). The TEF-1 $\alpha$ sequence is not available for the extype specimen isolate of $D$. rhusicola; therefore, these six isolates were considered as D. rhusicola in this study.

Culture and conidia morphological characterization. Twenty-nine isolates (Tables 3 and 4), which represent different species of Botryosphaeriaceae and Diaporthe identified by the three gene regions in this study, were selected for culture and conidial morphological characterization. All 29 isolates produced anamorphic structures on pistachio-leaf water agar within 2 to 3 weeks, and no teleomorph structures were observed. Based on colony growth characteristics, colony morphology, and conidia morphology, these fungi were grouped into seven distinct groups, which represented 12 species.

The first group was characterized by having slowly growing (colony diameter $<24 \mathrm{~mm}$ after $24 \mathrm{~h}$ at the optimal growth tem- perature of $25^{\circ} \mathrm{C}$ ) (Diaporthe spp. in Table 3), white to light-gray mycelium. Fungal colonies were suppressed or slightly raised and some developed prominent growth rings, with margins becoming black with age. Colonies produced dark pycnidia over time. Lightcream-colored conidia masses were observed on the pycnidia Conidia were subcylindrical to fusoid-ellipsoidal, widest in middle, and small $(<15$ by $5 \mu \mathrm{m})$. All these morphological characteristics were consistent with the description of species of Diaporthe $(24,58)$. Two species of Diaporthe, D. neotheicola and D. rhusicola were identified in this group. Conidia of D. rhusicola (average 8.6 by $3.3 \mu \mathrm{m}$ ) were larger than those of $D$. neotheicola (conidia average 7.9 by $2.5 \mu \mathrm{m}$ ) (Table 4 ).

The second group of fungi with fast-growing mycelium (colony diameter to $85 \mathrm{~mm}$ after $24 \mathrm{~h}$ at the optimal growth temperature of $30^{\circ} \mathrm{C} ; N$. dimidiatum in Table 3 ) had colonies with suppressed, dense mycelium. Colonies were initially white to olivaceous-buff, becoming greenish-olivaceous from the middle of the colonies within 7 days, and light black with age. Three types of conidia were observed: ellipsoidal to oval conidia, muriform conidia (globose, subglobose to obpyriform with muriform), and arthroconidia (conidia occurring in arthric chains, powdery to the touch, disarticulating, cylindrical-truncate) (Neoscytalidium spp. in Table 4). These characteristics were consistent with the description of $\mathrm{Ne}$ oscytalidium spp. of Botryosphaeriaceae. This group of fungi were identified as $N$. dimidiatum (Table 4).

The third group contained Dothiorella spp. These species produced moderate mycelium growth (colony diameter of $40.5 \mathrm{~mm}$

Table 2. (continued from preceding page)

\begin{tabular}{|c|c|c|c|c|c|c|c|c|c|}
\hline \multirow[b]{2}{*}{ Species } & \multicolumn{2}{|c|}{ Number $^{\mathrm{y}}$} & \multirow[b]{2}{*}{ Host } & \multirow[b]{2}{*}{ Location } & \multirow[b]{2}{*}{ Collector } & \multicolumn{3}{|c|}{ GenBank accession number ${ }^{\mathbf{Z}}$} & \multirow[b]{2}{*}{ Refs } \\
\hline & Isolate & Other & & & & ITS & TEF-1 $\alpha$ & BT2 & \\
\hline L. pseudotheobromae & CBS 447.62 & & $\begin{array}{l}\text { Citrus } \\
\text { aurantium }\end{array}$ & Suriname & C. Smulders & EF622081 & EF622060 & EU673112 & 7 \\
\hline L. theobromae & CBS $164.96^{\mathrm{T}}$ & & $\begin{array}{l}\text { Fruit on coral } \\
\text { reef coast }\end{array}$ & New Guinea & A. Aptroot & AY640255 & AY640258 & EU673110 & 7,30 \\
\hline L. theobromae & CBS 124.13 & & N/A & USA & J. J. Taubenhaus & DQ458890 & DQ458875 & DQ458858 & 7,30 \\
\hline $\begin{array}{l}\text { Neofusicoccum } \\
\text { andinum }\end{array}$ & CBS $117453^{\mathrm{T}}$ & CMW13455 & Eucalyptus sp. & $\begin{array}{c}\text { Merida state, } \\
\text { Venezuela }\end{array}$ & S. Mohali & AY693976 & GU251287 & GU251815 & 40 \\
\hline N. arbuti & CBS $116131^{\mathrm{T}}$ & PD282 & Arbutus nenziesii & Washington, USA & M. Elliot & GU251152 & GU251284 & GU251812 & 28 \\
\hline N. arbuti & PD281 & & A. nenziesii & Washington, USA & M. Elliot/A. Rossman & GU251151 & GU251283 & GU251811 & 28 \\
\hline N. mediterraneum & CBS $121718^{\mathrm{T}}$ & PD312 & Eucalyptus sp. & Greece & $\begin{array}{l}\text { P. W. Crous, M.J. Wing- } \\
\text { field \& A. J. L. Phillips }\end{array}$ & GU251176 & GU251308 & GU251836 & 18,28 \\
\hline N. mediterraneum & PD9 & & Fortunella sp. & Colusa, CA & T. J. Michailides & GU251180 & GU251312 & GU251840 & 28 \\
\hline N. nonquaesitum & $\mathrm{PD} 484^{\mathrm{T}}$ & & $\begin{array}{c}\text { Umbellularia } \\
\text { californica }\end{array}$ & Napa, CA & F. P. Trouillas & GU251163 & GU251295 & GU251823 & 28 \\
\hline N. nonquaesitum & PD90 & & Prunus dulcis & Butte, CA & T. J. Michailides & GU251157 & GU251289 & GU251817 & 28 \\
\hline$N$. parvum & CMW9081 & & P. nigra & New Zealand & G. J. Samuels & AY236943 & AY236888 & AY236917 & 53 \\
\hline N. parvum & CMW9080 & & P. nigra & New Zealand & G. J. Samuels & AY236942 & AY236887 & AY236916 & 53 \\
\hline N. ribis & CMW7772 & PD254 & Ribes sp. & New York, USA & $\begin{array}{l}\text { B. Slippers \& G. } \\
\text { Hudler }\end{array}$ & AY236935 & AY236877 & GU251786 & 53 \\
\hline N. ribis & CMW7773 & & Ribes sp. & New York, USA & B. Slippers \& G. Hudler & AY236936 & AY236878 & AY236907 & 53 \\
\hline N. viticlavatum & CBS $112878^{\mathrm{T}}$ & STE-U 5044 & Vitis vinifera & South Africa & F. Halleen & AY343381 & AY343342 & N/A & 66 \\
\hline N. viticlavatum & CBS 112977 & STE-U 5041 & $V$. vinifera & South Africa & F. Halleen & AY343380 & AY343341 & N/A & 66 \\
\hline N. vitifusiforme & CBS $110887^{\mathrm{T}}$ & STE-U 5252 & V. vinifera & South Africa & J. M. van Niekerk & AY343383 & AY343343 & N/A & 66 \\
\hline$N$. vitifusiforme & CBS 110880 & STE-U 5050 & V. vinifera & South Africa & J. M. van Niekerk & AY343382 & AY343344 & N/A & 66 \\
\hline $\begin{array}{l}\text { Neoscytalidium } \\
\text { dimidiatum }\end{array}$ & CBS 499.66 & & $\begin{array}{l}\text { Mangifera } \\
\text { indica }\end{array}$ & Mali & J. Brun & AY819727 & EU144063 & N/A & $20,30,43$ \\
\hline N. dimidiatum & CBS 204.33 & & Prunus sp. & Egypt & R. M. Nattrass & AY819728 & EU144064 & N/A & $20,30,43$ \\
\hline N. novaehollandiae & CMW26170 & CBS 122071 & $\begin{array}{l}\text { Crotalaria } \\
\text { medicaginea }\end{array}$ & Western Australia & T. I. Burgess & EF585540 & EF585580 & N/A & 43 \\
\hline N. novaehollandiae & CMW26169 & CBS 122070 & Grevillia agrifolia & Western Australia & N/A & EF585539 & EF585579 & N/A & 43 \\
\hline \multicolumn{10}{|l|}{ Diaporthe analyses } \\
\hline Celoporthe eucalypti & CMW26908 & CBS 127190 & $\begin{array}{l}\text { Eucalyptus } \\
\text { colony }\end{array}$ & $\begin{array}{l}\text { GuangDong, } \\
\text { China }\end{array}$ & $\begin{array}{l}\text { X. D. Zhou \& S. F. } \\
\text { Chen }\end{array}$ & HQ730837 & HQ730850 & N/A & 12 \\
\hline $\begin{array}{l}\text { Diaporthe } \\
\text { alleghaniensis }\end{array}$ & CBS $495.72^{\mathrm{T}}$ & & $\begin{array}{l}\text { Betula } \\
\text { alleghaniensis }\end{array}$ & Ontario, Canada & R. H. Arnold & FJ889444 & GQ250298 & N/A & 49 \\
\hline D. hickoriae & CBS $145.26^{\mathrm{T}}$ & & Carya glabra & Michigan, USA & L. E. Wehmeyer & FJ889446 & GQ250309 & N/A & 49 \\
\hline D. neotheicola & CBS $123208^{\mathrm{T}}$ & & $\begin{array}{l}\text { Foeniculum } \\
\text { vulgare }\end{array}$ & Vora, Portugal & A. J. L. Phillips & EU814480 & GQ250315 & N/A & 49,50 \\
\hline D. neotheicola & CBS $123209^{\mathrm{T}}$ & & F. vulgare & Vora, Portugal & A. J. L. Phillips & GQ250192 & GQ250316 & N/A & 49,50 \\
\hline D. rhusicola & CPC $18191^{\mathrm{T}}$ & CBS 129528 & Rhus pendulina & $\begin{array}{r}\text { Western Cape, } \\
\text { South Africa }\end{array}$ & P. W. Crous & JF951146 & N/A & N/A & 17 \\
\hline Phomopsis viticola & CBS $114016^{\mathrm{T}}$ & & Vitis vinifera & Bordeaux, France & P. Larignon & AF230751 & GQ250351 & N/A & 49,67 \\
\hline
\end{tabular}


after $24 \mathrm{~h}$ at the optimal temperature of $20^{\circ} \mathrm{C}$; Table 3). Mycelia were suppressed and dense. Colonies were initially thin-white to gray, becoming gray-black from the middle within 7 days, and black with age. Conidia were brown to dark walled, one-septate without longitudinal striation within the pycnidia, often before release from the conidiogenous cells; conidia were ovoid or ellipsoid and averaged 26.0 by $9.4 \mu \mathrm{m}$ (length/width $[\mathrm{L} / \mathrm{W}]=2.8$ ). Dothiorella iberica was identified in this group (Table 4).

The forth group had the typical characteristics of Lasiodiplodia spp., with mycelium growing fast (colony diameter to $85 \mathrm{~mm}$ after
$24 \mathrm{~h}$ of growth at the optimal temperature at $30^{\circ} \mathrm{C}$; Table 3 ). Colonies were fluffy with aerial mycelium, initially white to smokegray, becoming gray-black from the middle within 7 days, and dark with age. Conidia were initially hyaline, aseptate, ellipsoid to ovoid, becoming pigmented, one-septate with longitudinal striations with age. Conidia averaged 25.4 by $14.7 \mu \mathrm{m}(\mathrm{L} / \mathrm{W}=1.8)$; this group of fungi were identified as L. citricola (Table 4).

Each of three isolates of $L$. citricola from English walnut (isolates 7E78, 7E79, and 7E80) (11) and peach (Prunus persica; isolates 7E93, 7E94, and 7E95) (14) and three isolates of L. theobro-

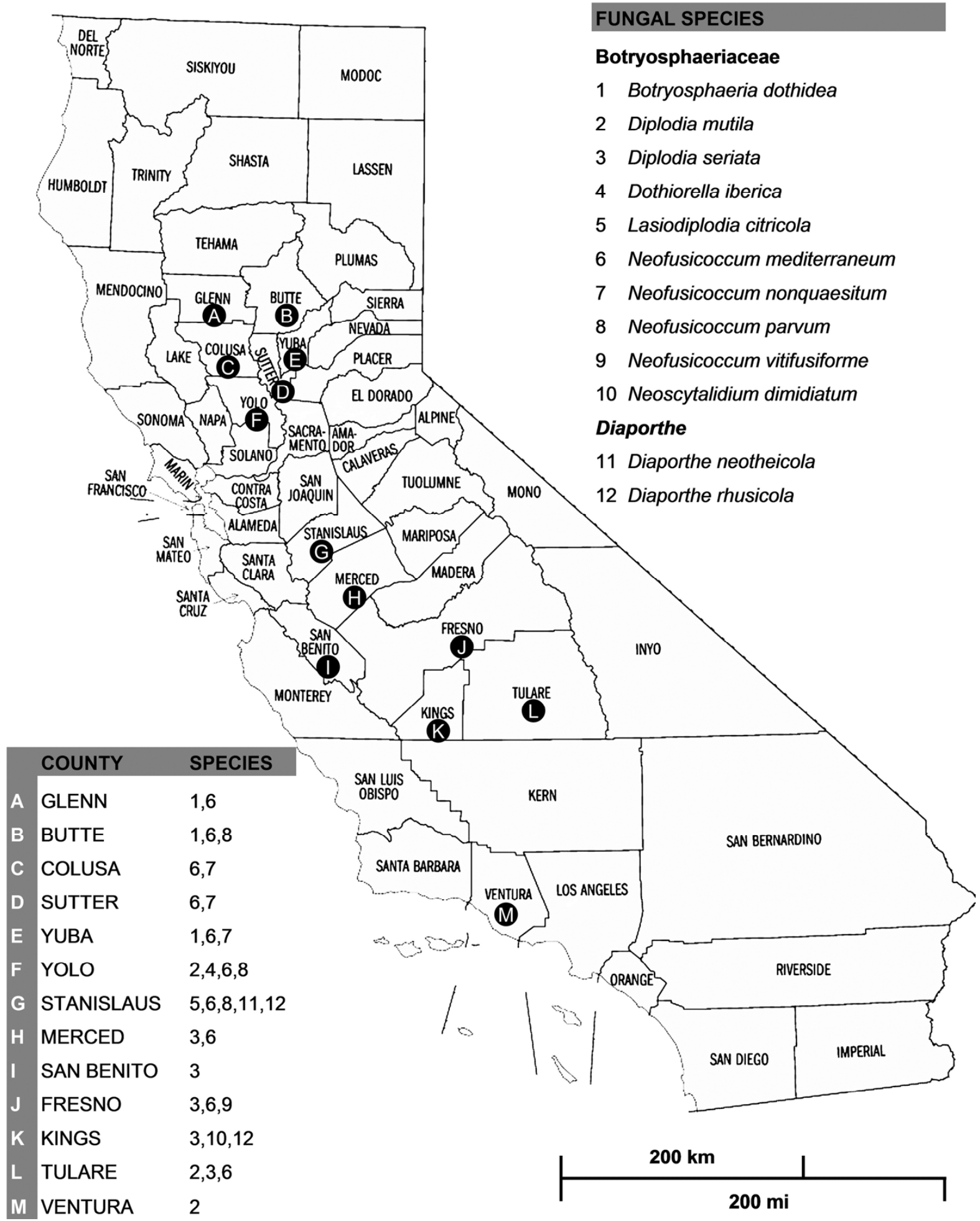

Fig. 1. Map of California indicating counties where English walnut trees were sampled and the species of Botryosphaeriaceae and Diaporthe obtained from each county. The 10 species of Botryosphaeriaceae and 2 species of Diaporthe are indicated as numbers 1 to 12 . 
mae from almond (isolates 7E86, 7E87, and 7E88) (13) were used to compare their morphological characteristics with $L$. citricola in this study (Tables 3 and 4). Results revealed that all Lasiodiplodia isolates had the same optimal growth temperature $\left(30^{\circ} \mathrm{C}\right)$, with similar culture and conidia morphology (Tables 3 and 4), except that the colonies of $L$. citricola grew faster than those of $L$. theobromae (Table 3 ) and conidia of $L$. citricola were larger than those of L. theobromae (Table 4).

The fifth group of fungi had moderate mycelium growth (colony diameter 34.5 to $67 \mathrm{~mm}$ after $24 \mathrm{~h}$ at the optimal temperature of

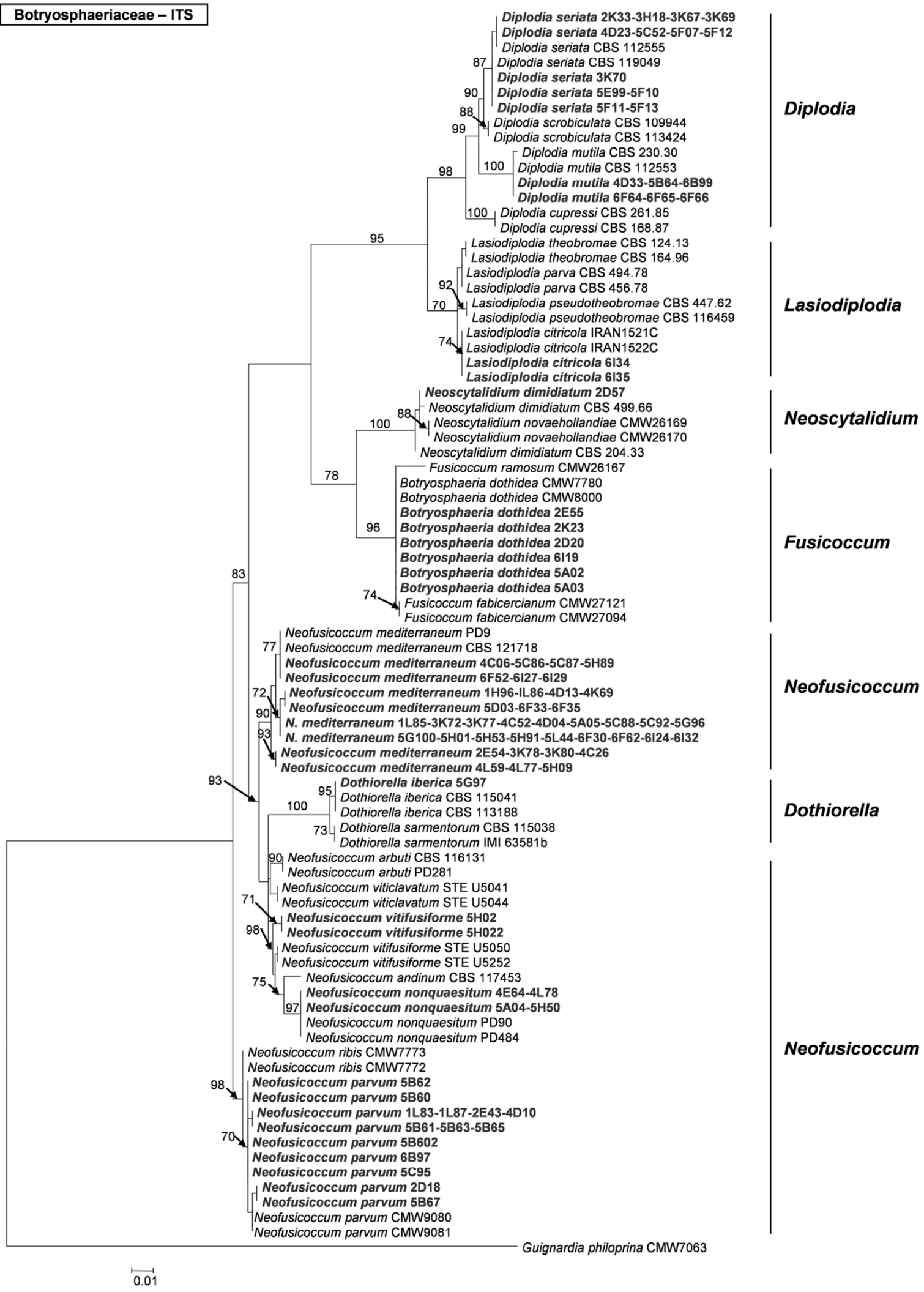

Fig. 2. Phylogenetic tree based on maximum likelihood analysis of internal transcribed spacer (ITS) nuclear ribosomal DNA sequences for various genera in the family Botryosphaeriaceae. Isolates in boldface were sequenced in this study. Bootstrap values $>70 \%$ are presented above branches. Bootstrap values $<70 \%$ are not shown. Guignardia philoprina (CMW7063) represents the outgroup. 
$25^{\circ} \mathrm{C}$; species of Diplodia in Table 3 ). Colonies were moderately dense with slightly aerial mycelium, initially white and turning dark olivaceous from the middle after 7 days. Conidia initially were hyaline, aseptate, oblong to ovoid, becoming dark brown, thick-walled, rarely one-septate without longitudinal striations after being released from the pycnidia with age. Two species of Diplodia, Diplodia mutila and D. seriata, were identified in this group. Colonies of $D$. mutila grew in a denser and more flat pattern than those of D. seriata, and conidia of D. mutila (average of 29.0 by $13.1 \mu \mathrm{m}$ ) were larger than those of $D$. seriata (average of 24.2 by $11.7 \mu \mathrm{m})$ (Table 4$)$.

Fungal groups six and seven produced moderate to fast-growing mycelia (colony diameter of 26.5 to $82 \mathrm{~mm}$ after $24 \mathrm{~h}$ at the optimal temperature of 25 to $30^{\circ} \mathrm{C}$; species of Botryosphaeria and

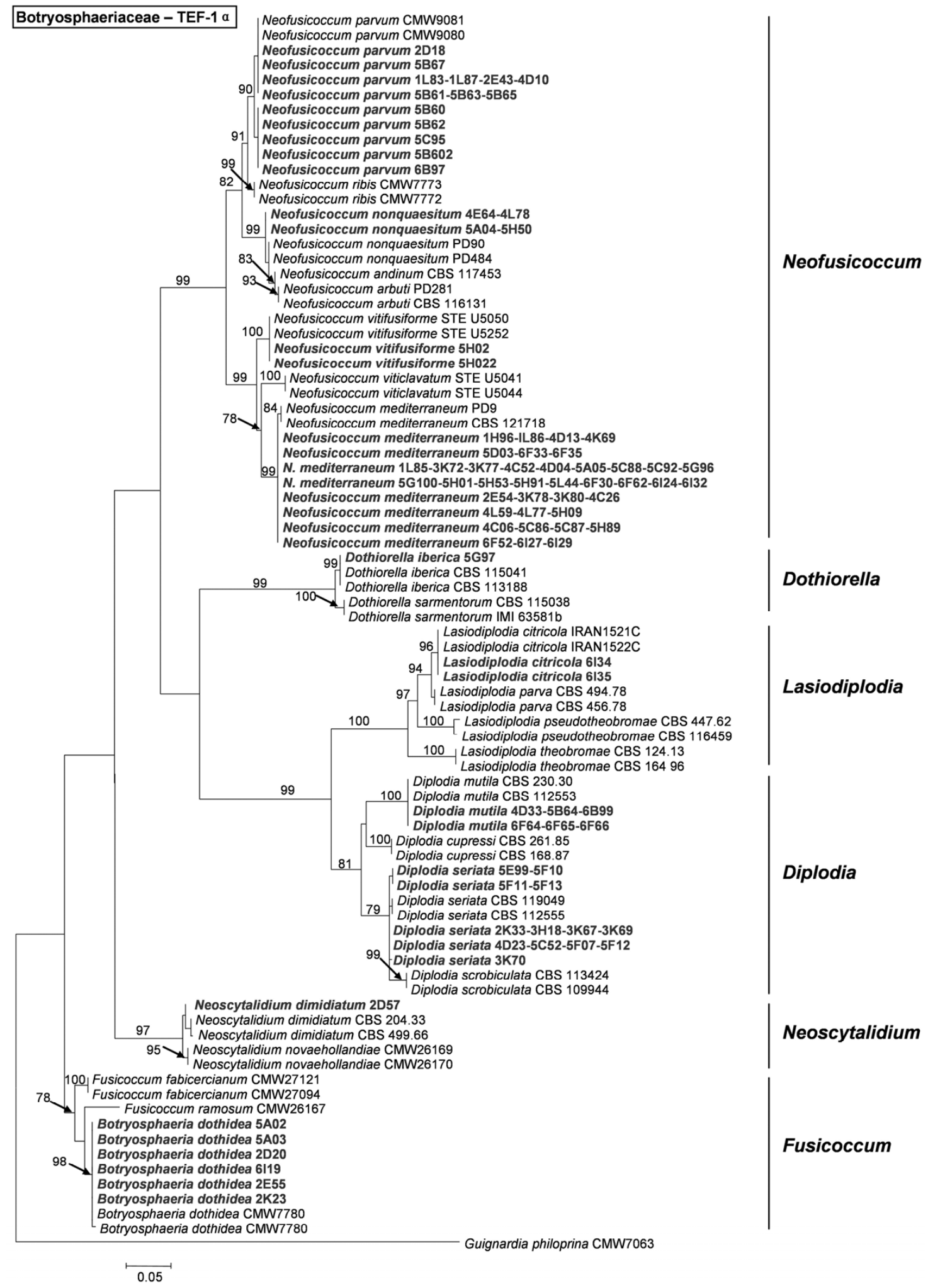

Fig. 3. Phylogenetic tree based on maximum likelihood analysis of translation elongation factor 1- $\alpha$ (TEF-1- $\alpha)$ gene sequences for various genera in the family Botryosphaeriaceae. Isolates in boldface were sequenced in this study. Bootstrap values $>70 \%$ are presented above branches. Bootstrap values $<70 \%$ are not shown. Guignardia philoprina (CMW7063) represents the outgroup. 
Neofusicoccum in Table 3). Colonies were moderately dense, with slight aerial mycelium, initially white, then turning gray-black from the middle after 7 days. Fungal group six and seven can be distinguished by conidia morphology. Conidia of group six were fusiform to ellipsoidal, with the average L/W smaller than 4.0, while fungi in group seven were narrow fusiform, with an average L/W of approximately 5.0.

Three species of Neofusicoccum were identified in fungal group six: Neofusicoccum nonquaesitum, N. parvum, and N. vitifusi- forme. The conidial shapes of these three species are similar to each other, whereas they can be distinguished from each other by their conidial sizes; conidia of $N$. nonquaesitum (average of $28.8 \times$ $7.7 \mu \mathrm{m}$ ) are larger than those of $N$. vitifusiforme (average of $22.6 \times$ $6.5 \mu \mathrm{m}$ ), and the conidia of $N$. parvum (average of $18.0 \times 5.9 \mu \mathrm{m}$ ) are the smallest (Table 4).

$B$. dothidea and $N$. mediterraneum were identified in fungal morphological group seven. Colonies of $B$. dothidea (colony diameter larger than $55 \mathrm{~mm}$ after $24 \mathrm{~h}$ at the optimal temperature

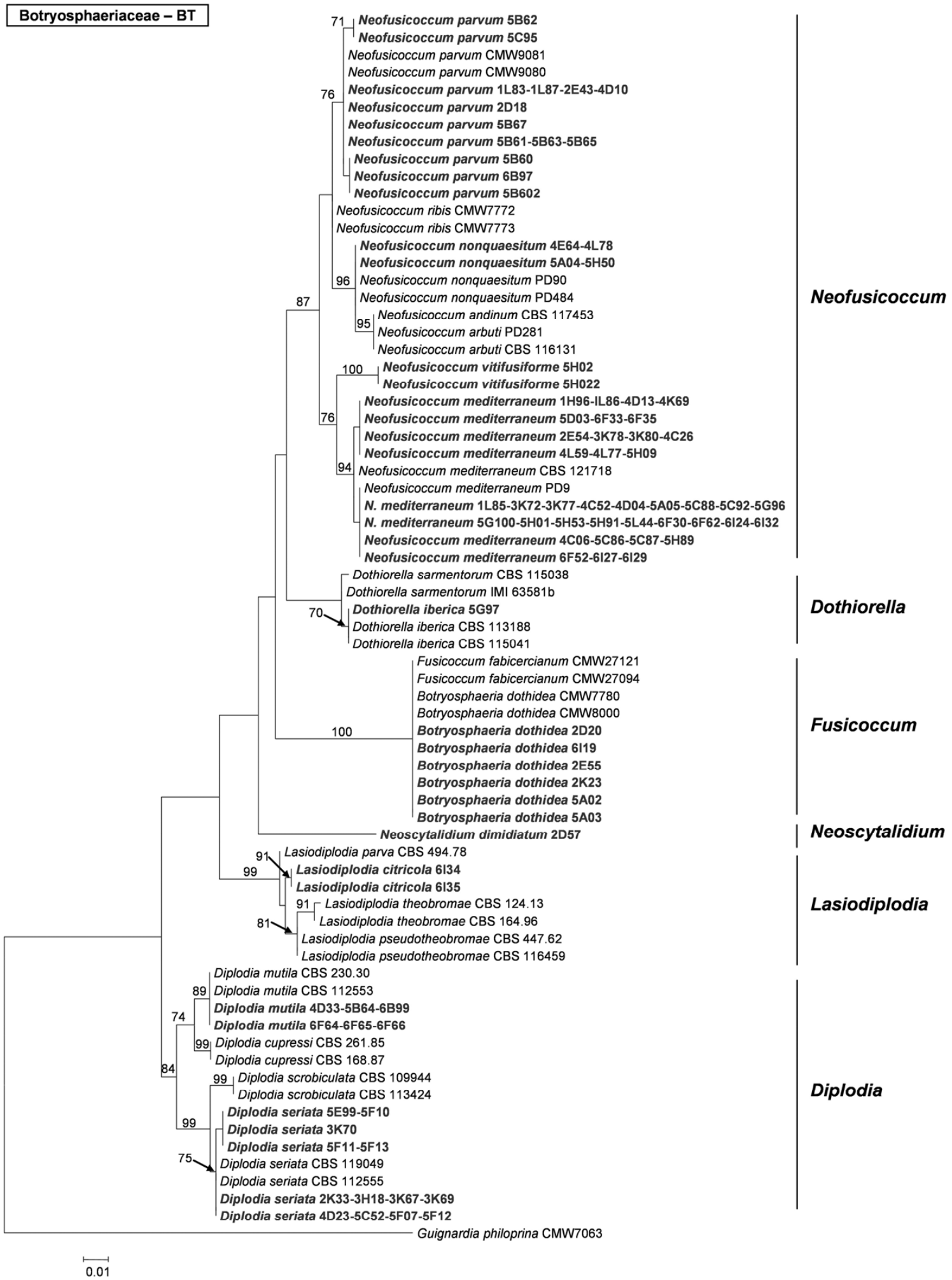

Fig. 4. Phylogenetic tree based on maximum likelihood analysis of $\beta$-tubulin (BT) gene sequences for various genera in the Botryosphaeriaceae. Isolates in boldface were sequenced in this study. Bootstrap values $>70 \%$ are presented above branches. Bootstrap values $<70 \%$ are not shown. Guignardia philoprina (CMW7063) represents the outgroup. 
of $30^{\circ} \mathrm{C}$ ) grew faster than $N$. mediterraneum (colony diameter $<55 \mathrm{~mm}$ after $24 \mathrm{~h}$ at the optimal temperature of 25 to $30^{\circ} \mathrm{C}$; Table 4).

Distribution of Botryosphaeriaceae and Diaporthe spp. By the sequence comparisons of ITS, TEF- $1 \alpha$, and BT gene regions, and combined with the colony growth characteristics, culture morphology, and conidia morphology, the 159 fungal isolates collected from diseased English walnut in California belonged to 10 different species of Botryosphaeriaceae and two species of Diaporthe. These include $B$. dothidea (4 isolates), D. mutila (1 isolate), D. seriata (12 isolates), Dothiorella iberica (1 isolate), L. citricola (2 isolates), N. mediterraneum (121 isolates), N. nonquaesitum (3 isolates), $N$. parvum (6 isolates), N. vitifusiforme (3 isolates), and Neoscytalidium dimidiatum (1 isolate). In addition, two species of Diaporthe, Diaporthe. neotheicola (1 isolate) and D. rhusicola (4 isolates), were recovered from infected California English walnut (Table 1). Neofusicoccum mediterraneum was dominant; 76\% (121 of the 159) of the isolates were identified as this fungus. N. mediterraneum was widely distributed and was recovered from 10 different counties (Table 1; Fig. 1). In California, in addition to English walnut, one isolate (4D33) from avocado was identified as Diplodia mutila, one isolate (4E64) from U. californica as N. nonquaesitum, and two isolates from almond (6I14 and 6I15) as Diaporthe rhusicola (Table 1). Among 15 isolates from pomegranate, 3 (6F64, 6F65, and 6F66) were identified as Diplodia mutila, 1 (2K33) as D. seriata, and $11(6 \mathrm{~F} 30,6 \mathrm{~F} 52,6 \mathrm{~F} 60$, and 8 other isolates which are not shown) as $N$. mediterraneum (Table 1). In addition to California, two isolates (5A02 and 5A03) from walnut in Greece were identified as $B$. dothidea and, among nine walnut isolates from Spain, eight (2D18, 5B60, 5B61, 5B62, 5B63, 5B65, $5 \mathrm{~B} 67$, and 5B602) were identified as $N$. parvum and one (5B64) as D. mutila (Table 1).

Inoculations of walnut branches and hulls with mycelium plugs. For the walnut branches and hulls inoculated with mycelium plugs, 21 isolates (Tables 1, 5, and 6) representing 10 species of Botryosphaeriaceae and 2 Diaporthe spp. on English walnut in California were selected. These included $B$. dothidea (2D20, 2E55, and 6I19), D. mutila (6B99 and 6F65), D. seriata (3H18 and 5F11), Dothiorella iberica (5G97), L. citricola (6I34 and 6I35), $N$. mediterraneum (5C87, 5H09, and 5H53), N. nonquaesitum (5A04), $N$. parvum (1L83, 1L87, and 2E43), N. vitifusiforme (5H02), $\mathrm{Ne}$ oscytalidium dimidiatum (2D57), Diaporthe neotheicola (6I30), and D. rhusicola (6I44) (Tables 1, 5, and 6). There were no significant differences between the results of the two experiments; therefore, these data were combined for statistical analyses. Data of the average lesion length for the combination of two experiments are shown in Tables 5 and 6 and Figures 7 and 8.

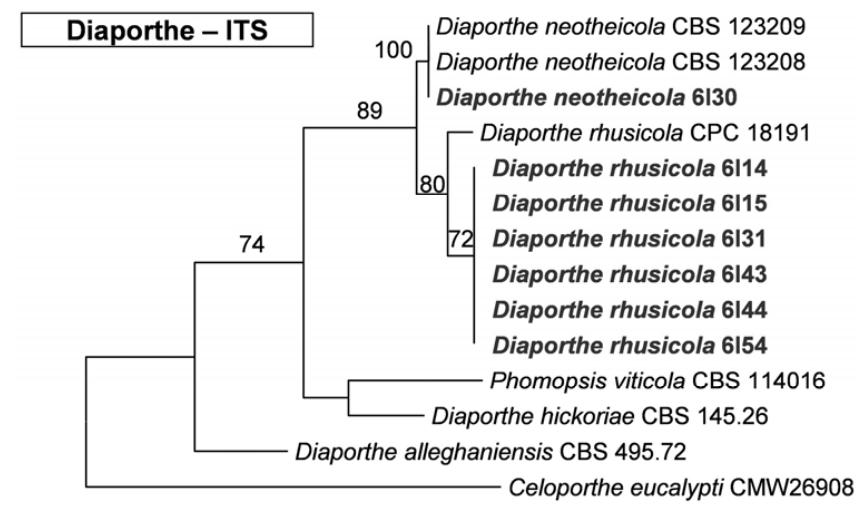

$$
\stackrel{\longmapsto}{0.01}
$$

Fig. 5. Phylogenetic tree based on maximum likelihood analysis of internal transcribed spacer (ITS) nuclear ribosomal DNA sequences for various species in the genus Diaporthe. Isolates in boldface were sequenced in this study. Bootstrap values $>70 \%$ are presented above branches. Bootstrap values $<70 \%$ are not shown. Celoporthe eucalypti (CMW26908) represents the outgroup.
On attached branches, all the tested fungi were able to produce longer lesions on the three tested cultivars than the noninoculated control branches (Table 5). All the tested isolates of L. citricola and Neofusicoccum parvum produced significantly longer lesions than the control (Table 5). Except for isolate 5H09 of N. mediterraneum on Chandler, all the tested isolates of $N$. mediterraneum produced significantly longer lesions than the control in all three cultivars (Tables 5). When results of the three cultivars were combined, $L$. citricola and $N$. parvum were clearly the most virulent species, followed by $N$. mediterraneum, Neoscytalidium dimidiatum, B. dothidea, and Neofusicoccum nonquaesitum (Fig. 7). Isolates of $L$. theobromae and N. parvum were able to kill the attached branches in all three tested cultivars. Isolates of $N$. mediterraneum killed the attached branches of Tulare and Vina 3 weeks after inoculation. The overall data revealed that Vina and Tulare are more susceptible than Chandler when their branches were inoculated with Botryosphaeriaceae fungi (Fig. 7).

The results from inoculations of fruit hulls on the trees were consistent with those from the branch inoculations. All the tested fungi produced a wider decay area than that in the control fruit (Table 6). With the exception of Diplodia mutila, D. seriata, Dothiorella iberica, Diaporthe neotheicola, and D. rhusicola, isolates of all the other species produced significantly larger lesions on hulls of the three cultivars (Table 6). After combining the results for the three cultivars, $N$. parvum and L. citricola were the most virulent, followed by $B$. dothidea, $N$. mediterraneum, Neoscytalidium dimidiatum, and Neofusicoccum nonquaesitum (Fig. 8). For Tulare and Vina, all the species of Botryosphaeriaceae were able to rot the entire hull of the fruits in 3 weeks. However, on Chandler, Diplodia seriata, D. mutila, and Dothiorella iberica decayed only part of the hulls 3 weeks after inoculation. Inoculations with the $D i$ aporthe spp. revealed that only Diaporthe neotheicola was able to decay the entire fruit hull of Vina in 3 weeks. These data revealed that Vina is the most susceptible and Chandler is relatively tolerant (Fig. 8).

Effect of inoculation method on infection of walnut. Five isolates of Botryosphaeriaceae were selected to test the effect of inoculation method on infection of English walnut; these included $B$. dothidea (2E55), L. citricola (6I35), N. mediterraneum (5C87, 5 H53), and $N$. parvum (1L83) (Table 7). The two experiments did not differ significantly and, thus, the two datasets were combined. The average lesion length for the combination of two experiments is shown in Table 7. Inoculations with the mycelium plug showed that all five tested isolates (Table 7) produced diseased lesions on the attached branches and decayed the fruit hulls but no lesions developed in the control branches or hulls (Table 7). However, when a spore suspension was used to inoculate branches and hulls, only $L$. citricola resulted in canker development and decayed the walnut hulls (Table 7); no cankers were produced and the hulls of

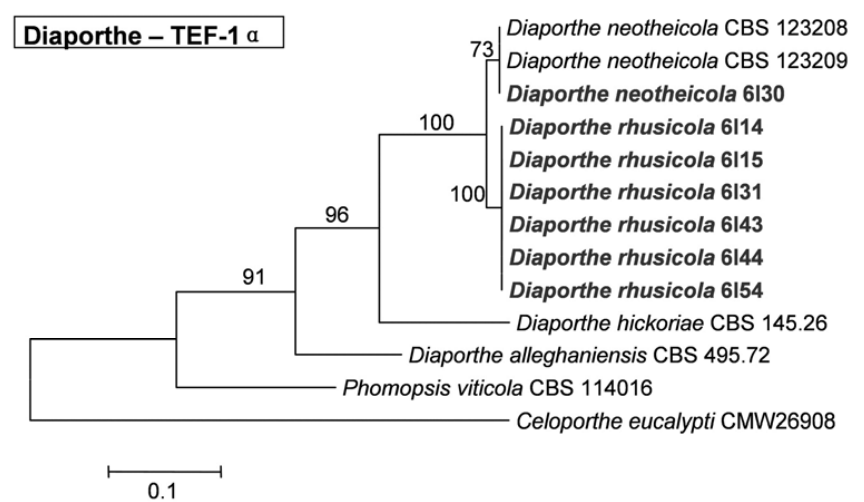

Fig. 6. Phylogenetic tree based on maximum likelihood analysis of translation elongation factor 1- $\alpha$ (TEF-1- $\alpha$ ) gene sequences for various species in the genus Diaporthe. Isolates in boldface were sequenced in this study. Bootstrap values $>$ $70 \%$ are presented above branches. Bootstrap values $<70 \%$ are not shown. Celoporthe eucalypti (CMW26908) represents the outgroup. 
English walnut fruit were not decayed by the spore suspension of $B$. dothidea, N. mediterraneum, or N. parvum.

\section{Discussion}

Research in this study represents the most comprehensive consideration of species of Botryosphaeriaceae from symptomatic English walnut trees affected by stem canker and branch and twig dieback in California to date. Using comparisons of ITS, TEF-1 $\alpha$, and BT sequence data and combined with the morphology and growth of colonies and morphology of conidia, 10 species of Botryosphaeriaceae belonging to six genera were identified from a relatively large collection of isolates. These include $B$. dothidea, Diplodia mutila, D. seriata, Dothiorella iberica, L. citricola, $N$. mediterraneum, $N$. nonquaesitum, $N$. parvum, $N$. vitifusiforme, and
Neoscytalidium dimidiatum. In addition, two species of Diaporthe (Diaporthaceae), Diaporthe neotheicola and D. rhusicola, were recovered from infected English walnut. Diplodia mutila, Dothiorella iberica, $N$. nonquaesitum, $N$. vitifusiforme, Diaporthe neotheicola, and D. rhusicola were reported for the first time from English walnut in California.

In previous studies in California, morphological features were used partially to characterize species of Botryosphaeriaceae $(28,31,33,65)$. In this study, the colony growth characteristics, culture morphology, and conidia morphology of the English walnut fungi were tested. These morphological characteristics offered valuable information to support the species identification which was determined by DNA sequence comparisons. Results of morphological comparisons in this study revealed that there is an over-

Table 3. Effect of temperature on mycelium growth of Botryosphaeriaceae and Diaporthe

\begin{tabular}{|c|c|c|c|c|c|c|c|c|c|c|}
\hline \multirow[b]{2}{*}{ Species } & \multirow[b]{2}{*}{ Isolate } & \multicolumn{8}{|c|}{ Temperature and measurements $(\mathrm{mm})^{\mathrm{y}}$} & \multirow[b]{2}{*}{ Source, OPT } \\
\hline & & $5^{\circ} \mathrm{C}$ & $10^{\circ} \mathrm{C}$ & $15^{\circ} \mathrm{C}$ & $20^{\circ} \mathrm{C}$ & $25^{\circ} \mathrm{C}$ & $30^{\circ} \mathrm{C}$ & $35^{\circ} \mathrm{C}$ & $40^{\circ} \mathrm{C}$ & \\
\hline \multicolumn{11}{|l|}{ Botryosphaeriaceae } \\
\hline Botryosphaeria dothidea & 2D20 & 8 & 28.5 & 36.5 & 66 & 77.5 & 82 & 38.5 & 10 & This study \\
\hline B. dothidea & $2 \mathrm{E} 55$ & 8 & 20.5 & 24 & 50.5 & 64 & 72.5 & 30 & 10 & This study \\
\hline B. dothidea & $5 \mathrm{~A} 03$ & 9 & 14 & 17 & 37 & 45 & 55 & 33 & 11 & This study \\
\hline B. dothidea & $\ldots$ & $\ldots$ & $\ldots$ & $\ldots$ & $\ldots$ & $\ldots$ & $\ldots$ & $\ldots$ & $\ldots$ & $53 ; 25-30^{\circ} \mathrm{C}$ \\
\hline Neofuscicoccum mediterraneum & $4 \mathrm{~K} 69$ & 7 & 11 & 15 & 20 & 25 & 34.5 & 12 & 10 & This study \\
\hline N. mediterraneum & $5 \mathrm{C} 87$ & 9 & 18.5 & 25 & 41 & 51.5 & 44.5 & 21 & 12 & This study \\
\hline N. mediterraneum & $5 \mathrm{H} 09$ & 9 & 12 & 15 & 23 & 27.5 & 30.5 & 12.5 & 10 & This study \\
\hline N. mediterraneum & $5 \mathrm{H} 53$ & 9 & 12 & 15.5 & 18.5 & 25 & 26.5 & 10 & 9 & This study \\
\hline N. mediterraneum & & & & & & & & & & $18 ;$ N/A \\
\hline N. nonquaesitum & 4L78 & 8 & 19 & 24.5 & 26 & 44.5 & 35 & 15 & 11 & This study \\
\hline N. nonquaesitum & $5 \mathrm{~A} 04$ & 8 & 16.5 & 24.5 & 28 & 42 & 28.5 & 17 & 12 & This study \\
\hline N. nonquaesitum & $\ldots$ & $\ldots$ & $\ldots$ & $\ldots$ & $\ldots$ & & $\ldots$ & & . & $28 ;$ N/A \\
\hline N. parvum & 1L87 & 7 & 25 & 34.5 & 50 & 63 & 62 & 28.5 & 14 & This study \\
\hline N. parvum & 2D18 & 7 & 22.5 & 30 & 55 & 69.5 & 78.5 & 25.5 & 13.5 & This study \\
\hline N. parvum & $5 \mathrm{~B} 60$ & 7 & 19 & 27 & 41 & 52 & 50 & 18 & 14 & This study \\
\hline N. parvum & $5 \mathrm{~B} 62$ & 7 & 17 & 22 & 45 & 55 & 59 & 20.5 & 12.5 & This study \\
\hline N. parvum & $5 \mathrm{C} 95$ & 8 & 15.5 & 20 & 26.5 & 33 & 39 & 17 & 12.5 & This study \\
\hline N. parvum & 6B97 & 9 & 14.5 & 16.5 & 28.5 & 37 & 37.5 & 16 & 13 & This study \\
\hline N. parvum & & & & & & & & & & $53 ; \mathrm{N} / \mathrm{A}$ \\
\hline N. vitifusiforme & $5 \mathrm{HO2}$ & 10 & 13.5 & 16.5 & 38 & 48.5 & 46 & 52.5 & 16 & This study \\
\hline N. vitifusiforme & $5 \mathrm{H} 022$ & 9 & 12 & 16 & 35 & 42 & 44 & 23 & 14 & This study \\
\hline N. vitifusiforme & $\ldots$ & $\ldots$ & $\ldots$ & $\ldots$ & $\ldots$ & $\ldots$ & $\ldots$ & & $\ldots$ & $66 ; 30^{\circ} \mathrm{C}$ \\
\hline Dothiorella iberica & 5G97 & 13 & 17.5 & 29 & 40.5 & 40 & 21 & 12 & 7 & This study \\
\hline D. iberica & $\ldots$ & & & & & & & & & $44 ; 20-25^{\circ} \mathrm{C}$ \\
\hline Diplodia mutila & 6B99 & 10 & 14 & 18.5 & 32 & 34.5 & 32.5 & 10 & 10 & This study \\
\hline D. mutila & $6 \mathrm{~F} 65$ & 10 & 11 & 15 & 31.5 & 38.5 & 35.5 & 10 & 11 & This study \\
\hline D. mutila & & & & & $\ldots$ & & $\ldots$ & & & $5 ; 25^{\circ} \mathrm{C}$ \\
\hline D. seriata & $3 \mathrm{H} 18$ & 10 & 30 & 36.5 & 56 & 67 & 66 & 17 & 11 & This study \\
\hline D. seriata & $3 \mathrm{~K} 70$ & 7 & 17.5 & 22.5 & 30.5 & 37.5 & 34.5 & 13 & 14 & This study \\
\hline D. seriata & $5 \mathrm{~F} 11$ & 7 & 17.5 & 24.5 & 37.5 & 51 & 42.5 & 21 & 14 & This study \\
\hline D. seriata & $\ldots$ & $\ldots$ & $\ldots$ & $\ldots$ & $\ldots$ & $\ldots$ & & & & $45 ; 25^{\circ} \mathrm{C}$ \\
\hline Lasiodiplodia citricola & $6 \mathrm{I} 34$ & 7 & 19 & 24.5 & 59 & 73 & 85 & 60 & 54.5 & This study \\
\hline L. citricola & $6 \mathrm{I} 35$ & 7 & 17 & 19.5 & 56.5 & 73 & 85 & 60 & 53.5 & This study \\
\hline L. citricola & 778 & 6 & 16 & 22 & 60 & 70 & 85 & 43 & 41 & 11 \\
\hline L. citricola & 7E79 & 7 & 17 & 20.5 & 50.5 & 68.5 & 84 & 52.5 & 40 & 11 \\
\hline L. citricola & 7E80 & 7 & 17 & 20.5 & 63.5 & 75 & 83.5 & 51 & 41.5 & 11 \\
\hline L. citricola & 7F93 & 7 & 37.5 & 50 & 48.5 & 59.5 & 85 & 55 & 43.5 & 14 \\
\hline L. citricola & $7 \mathrm{~F} 94$ & 7 & 15.5 & 19 & 52 & 63.5 & 81 & 45.5 & 41 & 14 \\
\hline L. citricola & 7F95 & 7 & 20 & 30 & 30 & 62 & 80 & 50 & 42 & 14 \\
\hline L. citricola & $\ldots$ & $\ldots$ & $\ldots$ & & $\ldots$ & & & & & $1 ; 25-30^{\circ} \mathrm{C}$ \\
\hline L. theobromae & 7E86 & 7 & 12.5 & 15.5 & 54.5 & 66 & 77.5 & 38.5 & 33.5 & 13 \\
\hline L. theobromae & 7E87 & 7 & 13 & 17 & 48.5 & 59 & 76.5 & 35 & 23 & 13 \\
\hline L. theobromae & $7 \mathrm{E} 88$ & 7 & 14 & 18 & 50 & 60 & 75 & 40 & 25 & 13 \\
\hline L. theobromae & $\ldots$ & $\ldots$ & $\ldots$ & & $\ldots$ & & & & & $7 ; \mathrm{N} / \mathrm{A}$ \\
\hline Neoscytalidium dimidiatum & 2D57 & 7 & 29 & 37.5 & 50 & 73.5 & $\mathbf{8 5}$ & $55^{\circ}$ & 50 & This study \\
\hline \multicolumn{11}{|l|}{ Diaporthe } \\
\hline Diaporthe neotheicola & $6 \mathrm{I} 30$ & 8 & 21 & 26 & 34.5 & 47.5 & 26 & 21 & 7 & This study \\
\hline D. neotheicola & & & & & (n) & & 20 & & $\ldots$ & $50 ; \mathrm{N} / \mathrm{A}$ \\
\hline D. rhusicola & $6 \mathrm{I} 14$ & 9 & 19 & 25.5 & 39 & 46.5 & 35 & 21.5 & 7 & This study \\
\hline D. rhusicola & $6 \mathrm{I} 43$ & 8 & 12 & 17 & 27 & 40 & 31 & 20 & 7 & This study \\
\hline D. rhusicola & $\ldots$ & $\ldots$ & $\ldots$ & $\ldots$ & $\ldots$ & $\ldots$ & $\ldots$ & $\ldots$ & $\ldots$ & $17 ;$ N/A \\
\hline
\end{tabular}

y The 7.0-mm culture plugs were removed and transferred to the centers of $90 \mathrm{~mm}$ petri dishes containing $2 \%$ potato dextrose agar. Measurements of colony diameter were taken after $48 \mathrm{~h}$ for isolates of Botryosphaeriaceae and $96 \mathrm{~h}$ for isolates of Diaporthe. Measurements in bold indicate optimal growth temperature (OPT) of each isolate.

${ }^{\mathrm{z}}$ Source of data and OPT of type. OPTs for the isolates have been linked to type material of the species. N/A = not available. 
lap between $B$. dothidea and $N$. mediterraneum (in both culture and conidia morphology). Although the culture morphology and conidia morphology of $N$. nonquaesitum with $N$. vitifusforme and $L$. citricola with $L$. theobromae were all very similar, these species could not be distinguished easily only by their morphological characteristics. The morphological overlap has also occurred with species of Botryosphaeriaceae in California in other studies $(28,31,33,41)$. Research results in this study further revealed that morphological features are not solely sufficient to define members within the family Botryosphaeriaceae to species.

Recently, research results indicated that DNA sequence comparisons of ITS, TEF- $1 \alpha$, and BT gene regions can identify species of Botryosphaeriaceae effectively and credibly $(30,31,33,41,65)$. In California, comparing the sequence data of the ITS, TEF- $1 \alpha$, and BT genes successfully clarified and identified species of Botryosphaeriaceae on fruit and nut trees, including isolates from avocado (33), coast live oak (Quercus agrifolia; 31 ), and olive $(41,65$ ) trees. In this study, all the species of Botryosphaeriaceae were clearly distinguished by the phylogenetic analyses of each of the three gene regions; phylogenetic analysis results of the three gene regions were consistent with each other as well as with the combined dataset. Genetic variations noted were observed within some species, especially in the ITS gene analyses for the species of $N$. mediterraneum, whereas these variations were not supported by the

Table 4. Conidial measurements of Botryosphaeriaceae and Diaporthe fungi used in this study and comparison with previous studies

\begin{tabular}{|c|c|c|c|c|c|}
\hline Species & Isolate $^{w}$ & Conidial size $(\mu \mathrm{m})(\mathrm{L} \times \mathbf{W})^{\mathrm{x}}$ & $\begin{array}{c}\text { Mean } \pm \text { SD }(\mu \mathrm{m}) \\
(\mathbf{L} \times \mathbf{W})^{\mathbf{y}}\end{array}$ & $\mathbf{L} / \mathbf{W}^{\mathbf{z}}$ & Source of data \\
\hline \multicolumn{6}{|l|}{ Botryosphaeriaceae } \\
\hline Botryosphaeria dothidea & 2D20 & $(19.5-) 21.5-26.5(-28) \times(3.5-) 4.5-5(-5.5)$ & $24.0 \pm 2.4 \times 4.8 \pm 0.5$ & 5 & This study \\
\hline B. dothidea & $2 \mathrm{E} 55$ & $(22.5-) 24-28.5(-32) \times(4.5-) 4.5-6.5(-7.5)$ & $26.4 \pm 2.4 \times 5.5 \pm 0.8$ & 4.8 & This study \\
\hline B. dothidea & $5 \mathrm{~A} 03$ & $(17-) 21.0-27.5(-29) \times(3.5-) 4-5$ & $24.3 \pm 3.0 \times 4.5 \pm 0.5$ & 5.4 & This study \\
\hline B. dothidea & Type & $(20-) 23-27(-30) \times 4-5(-6)$ & $24.7 \times 4.9$ & 5 & 53 \\
\hline Neofuscicoccum mediterraneum & $4 \mathrm{~K} 69$ & $(22-) 23-26(-27) \times(4-) 4.5-5(-5.5)$ & $24.7 \pm 1.5 \times 4.7 \pm 0.2$ & 5.3 & This study \\
\hline N. mediterraneum & $5 \mathrm{C} 87$ & $(20.5-) 22-26(-27) \times(4-) 4.5-5.5(-6.5)$ & $24.1 \pm 1.9 \times 4.9 \pm 0.5$ & 4.9 & This study \\
\hline N. mediterraneum & $5 \mathrm{H} 09$ & $(19.5-) 20.5-24.5(-27) \times(3.5-) 4.5-5(-5.5)$ & $22.7 \pm 2.0 \times 4.7 \pm 0.3$ & 4.8 & This study \\
\hline N. mediterraneum & $5 \mathrm{H} 53$ & $(19.5-) 21-26.5(-32) \times(4.0-) 4.5-5(-6.5)$ & $23.8 \pm 2.9 \times 4.8 \pm 0.8$ & 5 & This study \\
\hline N. mediterraneum & Type & $(19-) 22-26(-27) \times(5.5-) 6(-6.5)$ & $24 \times 6$ & 4 & 18 \\
\hline N. nonquaesitum & $4 \mathrm{~L} 78$ & $(21.5-) 25.5-33(-36.5) \times(4.0-) 6-9(-9.5)$ & $29.1 \pm 3.8 \times 8.1 \pm 1.2$ & 3.5 & This study \\
\hline N. nonquaesitum & $5 \mathrm{~A} 04$ & $(24-) 26-30.5(-34) \times(4.5-) 6-8.5(-8.5)$ & $28.4 \pm 2.2 \times 7.3 \pm 1.1$ & 3.8 & This study \\
\hline N. nonquaesitum & Type & $(17.2-) 20.5-25.9(-29.1) \times(5.6-) 6.6-8.6(-10.6)$ & $23.2 \pm 2.7 \times 7.6 \pm 1.0$ & 3.1 & 28 \\
\hline N. parvum & $1 \mathrm{~L} 87$ & $(13.5-) 14-17(-20) \times(4.5-) 5.0-7.0(-7.5)$ & $15.6 \pm 1.5 \times 6.1 \pm 0.8$ & 2.6 & This study \\
\hline N. parvum & 2D18 & $15-) 15.5-17.5(-19.5) \times(5.0-) 5.5-6.5(-7.5)$ & $16.7 \pm 0.9 \times 6.0 \pm 0.4$ & 2.8 & This study \\
\hline N. parvum & $5 \mathrm{~B} 60$ & $(14.5-) 17-20(-21) \times(4-) 5.5-6.5(-7.5)$ & $18.6 \pm 1.3 \times 6.0 \pm 0.8$ & 3.1 & This study \\
\hline N. parvum & $5 \mathrm{~B} 62$ & $(15-) 18-21(-22) \times(4.5-) 5.5-7(-7.5)$ & $19.6 \pm 1.6 \times 6.3 \pm 0.8$ & 3.1 & This study \\
\hline N. parvum & $5 \mathrm{C} 95$ & $(15-) 17-21(-23) \times(4.5-) 5-6.5(-7.5)$ & $19.1 \pm 2.1 \times 5.7 \pm 0.5$ & 3.4 & This study \\
\hline N. parvum & $6 \mathrm{~B} 97$ & $(14-) 16.5-20.5(-22) \times(4.5-) 5-6(-7.5)$ & $18.5 \pm 1.8 \times 5.5 \pm 0.5$ & 3.4 & This study \\
\hline N. parvum & Type & $(12-) 15-19(-24) \times 4-6$ & $16.9 \times 5.4$ & 3.1 & 53 \\
\hline N. vitifusiforme & $5 \mathrm{H} 02$ & $(17-) 19.5-24.5(-27) \times(5.5-) 6-7.5(-8.5)$ & $22.1 \pm 2.5 \times 6.8 \pm 0.9$ & 3.3 & This study \\
\hline N. vitifusiforme & $5 \mathrm{H} 022$ & $(19.5-) 21.5-24.5(-27) \times(4.5-) 5.5-7(-7.5)$ & $23.1 \pm 1.6 \times 6.2 \pm 0.7$ & 3.7 & This study \\
\hline N. vitifusiforme & Type & $(18-) 19-21(-22) \times(4.5-) 5.5-6.5(-8)$ & $20 \times 6.0$ & 3.3 & 66 \\
\hline Dothiorella iberica & $5 \mathrm{G} 97$ & $(24-) 24.5-27.5(-29.5) \times(8.5-) 8.5-10.5(-11)$ & $26.0 \pm 1.5 \times 9.4 \pm 0.8$ & 2.8 & This study \\
\hline D. iberica & Type & $(17.2-) 23.0-23.4(-28.6) \times(8.1-) 10.8-11.0(-16.0)$ & $23.2 \pm 1.9 \times 10.9 \pm 1.2$ & 2.2 & 44 \\
\hline Diplodia mutila & $6 \mathrm{~B} 99$ & $(26.5-) 28-30(-32) \times(11.5-) 12-13(-13.5)$ & $29.5 \pm 1.4 \times 12.4 \pm 0.5$ & 2.4 & This study \\
\hline D. mutila & $6 \mathrm{~F} 65$ & $(25.5-) 27-30(-32) \times(12-) 12.5-14.5(-15)$ & $28.6 \pm 1.4 \times 13.7 \pm 0.8$ & 2.1 & This study \\
\hline D. mutila & Type & $(23.5-) 25.1-25.7(-27.4) \times(12.4-) 13.2-13.5(-14.3)$ & $25.4 \pm 1.0 \times 13.5 \pm 0.5$ & 1.9 & 5 \\
\hline D. seriata & $3 \mathrm{H} 18$ & $(19.5-) 19.5-22.5(-24.5) \times(10.5-) 11.5-12.5(-13.5)$ & $21.0 \pm 1.6 \times 12.0 \pm 0.7$ & 1.8 & This study \\
\hline D. seriata & $3 \mathrm{~K} 70$ & $(23.5-) 24-26.5(-29.5) \times(9.5-) 10.5-12(-12.5)$ & $25.2 \pm 1.4 \times 11.2 \pm 0.7$ & 2.2 & This study \\
\hline D. seriata & $5 \mathrm{~F} 11$ & $(23.5-) 25.5-28(-29.5) \times(9.5-) 11-12.5(-12.5)$ & $26.5 \pm 1.7 \times 11.8 \pm 0.7$ & 2.2 & This study \\
\hline D. seriata & Type & $(21.5-) 22-27(-28) \times(11-) 11.5-14.5(-15.5)$ & $24.9 \pm 1.9 \times 12.9 \pm 1.1$ & 1.9 & 45 \\
\hline Lasiodiplodia citricola & $6 \mathrm{I} 34$ & $(18.5-) 22.5-26(-27) \times(12-) 12.5-15(-16)$ & $24.8 \pm 2.1 \times 14.4 \pm 0.7$ & 1.7 & This study \\
\hline L. citricola & $6 \mathrm{I} 35$ & $(17-) 23.5-27(-28.5) \times(13-) 14-15.5(-16)$ & $26.0 \pm 2.2 \times 14.9 \pm 0.7$ & 1.8 & This study \\
\hline L. citricola & $7 \mathrm{E} 78$ & $(25-) 26.5-29.5(-31) \times(13-) 13-14.5(-15)$ & $28.0 \pm 1.5 \times 13.8 \pm 0.5$ & 2 & 11 \\
\hline L. citricola & 7E79 & $(24-) 26-30(-32) \times(13-) 14-15(-16)$ & $28.1 \pm 1.8 \times 14.6 \pm 0.4$ & 1.9 & 11 \\
\hline L. citricola & $7 \mathrm{E} 80$ & $(26.5-) 27-30(-32) \times(12-) 13-15(-16)$ & $28.5 \pm 1.4 \times 14.4 \pm 0.3$ & 2 & 11 \\
\hline L. citricola & 7F93 & $(19-) 24.5-29(-30) \times(13-) 14-16(-17)$ & $27.0 \pm 2.5 \times 14.9 \pm 0.9$ & 1.8 & 14 \\
\hline L. citricola & 7F94 & $(24-) 26-28.5(-30) \times(14.5-) 15-17.5(-17.5)$ & $27.4 \pm 1.7 \times 16.1 \pm 1.1$ & 1.7 & 14 \\
\hline L. citricola & $7 \mathrm{~F} 95$ & $(20-) 25-29(-30.5) \times(13.5-) 14-17(-18)$ & $27.0 \pm 2.0 \times 15.5 \pm 0.9$ & 1.7 & 14 \\
\hline L. citricola & Type & $(20-) 22-27(-31) \times(10.9-) 12-17(-19)$ & $24.5 \pm 0.2 \times 15.4 \pm 1.8$ & 1.6 & 1 \\
\hline L. theobromae & $7 \mathrm{E} 86$ & $(16-) 21-26.5(-30) \times(9.5-) 13-14.5(-16)$ & $23.5 \pm 2.0 \times 13.8 \pm 0.7$ & 1.7 & 13 \\
\hline L. theobromae & $7 \mathrm{E} 87$ & $(17.5-) 20-24(-28) \times(9-) 11.5-13(-15.5)$ & $22.0 \pm 1.9 \times 12.5 \pm 0.4$ & 1.8 & 13 \\
\hline L. theobromae & 7E88 & $(17.5-) 21.5-25(-27) \times(10-) 12.5-14(-15)$ & $23.3 \pm 1.8 \times 13.3 \pm 0.6$ & 1.8 & 13 \\
\hline L. theobromae & Type & $(19-) 21-31(-32.5) \times(12-) 13-15.5(-18.5)$ & $26.2 \pm 2.6 \times 14.2 \pm 1.2$ & 1.9 & 7 \\
\hline Neoscytalidium dimidiatum & 2D57 & & & & \\
\hline Ellipsoidal conidia & $\ldots$ & $(7-) 9-12(-15) \times(2.5-) 3.5-4.5(-5)$ & $10.9 \pm 0.8 \times 3.9 \pm 0.4$ & 2.8 & This study \\
\hline Muriform conidia & $\ldots$ & $(7-) 9.5-12.5(-20) \times(4-) 6.5-10.5(-14.5)$ & $11.1 \pm 0.6 \times 8.5 \pm 0.5$ & & This study \\
\hline Arthroconidia & $\ldots$ & $(3-) 5-7(-12) \times(2-) 3.5-5.5(-7)$ & $6.0 \pm 0.3 \times 4.0 \pm 0.2$ & 1.5 & This study \\
\hline \multicolumn{6}{|l|}{ Diaporthe } \\
\hline Diaporthe neotheicola & $6 \mathrm{I} 30$ & $(5.5-) 6.5-9.5(-12) \times 2-3(-5)$ & $7.9 \pm 1.6 \times 2.5 \pm 0.5$ & 3.1 & This study \\
\hline D. neotheicola & Type & $(6.6-) 7.6-8(-9.5) \times(1.9-) 2.2-2.3(-2.6)$ & $7.8 \pm 0.6 \times 2.2 \pm 0.2$ & 3.5 & 50 \\
\hline D. rhusicola & $6 \mathrm{I} 14$ & $(7.5-) 8-9(-10) \times(2.5-) 3-4$ & $8.5 \pm 0.7 \times 3.2 \pm 0.2$ & 2.7 & This study \\
\hline D. rhusicola & $6 \mathrm{I} 43$ & $(7-) 8-9.5(-11) \times(2.5-) 3-3.5(-4)$ & $8.7 \pm 0.7 \times 3.4 \pm 0.3$ & 2.6 & This study \\
\hline D. rhusicola & Type & $(7-) 8-9(-10) \times 3(-3.5)$ & $8.5 \times 3$ & 2.8 & 17 \\
\hline
\end{tabular}

w Type = isolates for measurements are ex-type or from samples that have been linked to type material of the species. The information of the type is in boldface.

${ }^{\mathrm{x}} \mathrm{L} \times \mathrm{W}=$ length by width; minimum-(average - standard deviation [SD])-(average $\left.\pm \mathrm{SD}\right)-$ maximum.

${ }^{y} \mathrm{~L} \times \mathrm{W}=$ length by width.

${ }^{\mathrm{z}} \mathrm{L} / \mathrm{W}=$ average length/average width. 
TEF-1 $\alpha$ or BT gene analyses, suggesting that these reflect intraspecific sequence difference rather than interspecific variation. Multiple phylogenetic subgroups were also observed within $N$. parvum in the phylogenetic analyses of ITS, TEF- $1 \alpha$, and BT gene regions. Although cryptic species may exist, further genetic analyses with additional genes using a more extensive population sample may help to resolve this intraspecific or interspecific variation.

Results of pathogenicity tests revealed that L. citricola is the most pathogenic to the tested English walnut branches and hulls. Before this study, L. citricola was isolated from the graft union of English walnut in Tulare County in California (11). This fungus, with Neoscytalidium dimidiatum, caused cankers at the graft union and killed the English walnut scion under an open environment in a nursery (11). Species of Lasiodiplodia were reported in California from other nut and fruit trees, including $L$. citricola on peach (14),
L. crassispora on grapevine (64), and L. theobromae on almond (13) and grapevine (62). Inoculations with these fungi showed that all are highly virulent to their respective hosts. Although only two isolates of Lasiodiplodia were collected in this study from walnut in Stanislaus County, it is recommended that the frequency of these fungi should be monitored to determined their build up and spread in other California counties.

In California, Neofusicoccum parvum has been reported from almond (28), avocado (33,34), citrus (Citrus sp.) (3), English walnut (28), and grapevine (61). Inoculations of $N$. parvum on almond, avocado, citrus, and grapevine indicated that it is highly virulent $(3,28,34,61)$. In our study, $N$. parvum was second only to L. citricola in terms of its virulence, which further supports the view that $N$. parvum is one of the most damaging species of Botryosphaeriaceae on trees (54). Similarly to $L$. citricola, a relatively small

Table 5. Average canker length on branches of Juglans regia 'Chandler', 'Tulare', and 'Vina' caused by mycelium plug inoculations with Botryosphaeriaceae and Diaporthe fungi

\begin{tabular}{|c|c|c|c|c|}
\hline \multirow[b]{2}{*}{ Species } & \multirow[b]{2}{*}{ Isolate number } & \multicolumn{3}{|c|}{ Canker length $(\mathrm{mm})^{\mathrm{z}}$} \\
\hline & & Chandler & Tulare & Vina \\
\hline \multirow[t]{3}{*}{ Botryosphaeria dothidea } & $2 \mathrm{D} 20$ & $24.2 \mathrm{~m}-\mathrm{u}$ & $37 \mathrm{j}-\mathrm{t}$ & $58.5 \mathrm{i}-\mathrm{k}$ \\
\hline & $2 \mathrm{E} 55$ & $32 \mathrm{k}-\mathrm{u}$ & $34 \mathrm{k}-\mathrm{u}$ & $301-u$ \\
\hline & $6 \mathrm{I} 19$ & $22.1 \mathrm{~m}-\mathrm{u}$ & $43.9 \mathrm{j}-\mathrm{o}$ & $301-\mathrm{u}$ \\
\hline \multirow[t]{2}{*}{ Diplodia mutila } & $6 B 99$ & $14.8 \mathrm{q}-\mathrm{u}$ & $19.8 \mathrm{n}-\mathrm{u}$ & $20 n-u$ \\
\hline & $6 \mathrm{~F} 65$ & $22 \mathrm{~m}-\mathrm{u}$ & $16.9 \mathrm{p}-\mathrm{u}$ & $20 n-u$ \\
\hline \multirow[t]{2}{*}{ D. seriata } & $3 \mathrm{H} 18$ & $17.3 \mathrm{n}-\mathrm{u}$ & $20 \mathrm{n}-\mathrm{u}$ & $17.8 \mathrm{n}-\mathrm{u}$ \\
\hline & $5 \mathrm{~F} 11$ & $17.6 \mathrm{n}-\mathrm{u}$ & $19.9 \mathrm{n}-\mathrm{u}$ & $18 \mathrm{n}-\mathrm{u}$ \\
\hline Dothiorella iberica & $5 \mathrm{G} 97$ & $15 \mathrm{q}-\mathrm{u}$ & $15.2 \mathrm{q}-\mathrm{u}$ & $18 \mathrm{n}-\mathrm{u}$ \\
\hline \multirow[t]{2}{*}{ Lasiodiplodia citricola } & $6 \mathrm{I} 34$ & $155 \mathrm{bc}$ & $157.5 \mathrm{bc}$ & $177 \mathrm{ab}$ \\
\hline & $6 \mathrm{I} 35$ & $86 \mathrm{gh}$ & $132.5 \mathrm{~cd}$ & 196 a \\
\hline \multirow[t]{3}{*}{ Neofusicoccum mediterraneum } & $5 \mathrm{C} 87$ & $41 \mathrm{j}-\mathrm{q}$ & $83 \mathrm{~g}-\mathrm{i}$ & $53 \mathrm{j}-1$ \\
\hline & $5 \mathrm{H} 09$ & $32 \mathrm{k}-\mathrm{u}$ & $48 \mathrm{j}-\mathrm{m}$ & $37 \mathrm{j}-\mathrm{t}$ \\
\hline & $5 \mathrm{H} 53$ & $40 \mathrm{j}-\mathrm{r}$ & $43.3 \mathrm{j}-\mathrm{p}$ & $37.5 \mathrm{j}-\mathrm{s}$ \\
\hline N. nonquaesitum & $5 \mathrm{~A} 04$ & $43 \mathrm{j}-\mathrm{p}$ & $27.2 \mathrm{l}-\mathrm{u}$ & $261-u$ \\
\hline \multirow{3}{*}{ N. parvum } & $1 \mathrm{~L} 83$ & $114.5 \mathrm{~d}-\mathrm{f}$ & $190 \mathrm{a}$ & $157 \mathrm{bc}$ \\
\hline & 1L87 & $80.5 \mathrm{~g}-\mathrm{i}$ & $82 \mathrm{~g}-\mathrm{i}$ & $177 \mathrm{ab}$ \\
\hline & $2 \mathrm{E} 43$ & $99 \mathrm{fg}$ & $130.5 \mathrm{c}-\mathrm{e}$ & $104 \mathrm{e}-\mathrm{g}$ \\
\hline N. vitifusiforme & $5 \mathrm{H} 02$ & $15.6 \mathrm{q}-\mathrm{u}$ & $25 \mathrm{~m}-\mathrm{u}$ & $19 \mathrm{n}-\mathrm{u}$ \\
\hline Neoscytalidium dimidiatum & 2D57 & $44.5 \mathrm{j}-\mathrm{n}$ & $30.31-\mathrm{u}$ & $63.5 \mathrm{~h}-\mathrm{j}$ \\
\hline Diaporthe neotheicola & $6 \mathrm{I} 30$ & $13.3 \mathrm{r}-\mathrm{u}$ & $16.2 \mathrm{p}-\mathrm{u}$ & $15.5 \mathrm{q}-\mathrm{u}$ \\
\hline D. rhusicola & $6 \mathrm{I} 44$ & $13.9 \mathrm{q}-\mathrm{u}$ & $16.5 \mathrm{p}-\mathrm{u}$ & $15.5 \mathrm{q}-\mathrm{u}$ \\
\hline Control & $\ldots$ & $9.9 \mathrm{t}-\mathrm{u}$ & $10.3 \mathrm{~s}-\mathrm{u}$ & $9 \mathrm{u}$ \\
\hline
\end{tabular}

${ }^{\mathrm{z}}$ Numbers followed by different letters are significantly different $(P=0.05)$.

Table 6. Average rot diameter of fruit hulls of Juglans regia 'Chandler', 'Tulare', and 'Vina' caused by mycelium plug inoculations with Botryosphaeriaceae and Diaporthe fungi

\begin{tabular}{|c|c|c|c|c|}
\hline \multirow[b]{2}{*}{ Species } & \multirow[b]{2}{*}{ Isolate number } & \multicolumn{3}{|c|}{ Hull rot diameter $(\mathbf{m m})^{\mathrm{z}}$} \\
\hline & & Chandler & Tulare & Vina \\
\hline \multirow[t]{3}{*}{ Botryosphaeria dothidea } & $2 \mathrm{D} 20$ & $36.6 j-p$ & $44.7 \mathrm{e}-\mathrm{j}$ & $56.5 \mathrm{ab}$ \\
\hline & 2E55 & $37.4 \mathrm{j}-\mathrm{o}$ & $52.0 \mathrm{a}-\mathrm{f}$ & $52 \mathrm{a}-\mathrm{f}$ \\
\hline & $6 \mathrm{I} 19$ & $35.6 \mathrm{k}-\mathrm{p}$ & $44.4 \mathrm{f}-\mathrm{j}$ & $55.6 \mathrm{a}-\mathrm{c}$ \\
\hline \multirow[t]{2}{*}{ Diplodia mutila } & 6B99 & $14.8 v-\mathrm{x}$ & $39.3 \mathrm{i}-\mathrm{m}$ & $42.5 \mathrm{~g}-\mathrm{k}$ \\
\hline & $6 \mathrm{~F} 65$ & $17.5 \mathrm{u}-\mathrm{w}$ & $25 \mathrm{r}-\mathrm{u}$ & $40.6 \mathrm{~h}-1$ \\
\hline \multirow{2}{*}{ D. seriata } & $3 \mathrm{H} 18$ & $19.1 \mathrm{t}-\mathrm{v}$ & $29.7 \mathrm{n}-\mathrm{r}$ & $41.7 \mathrm{~g}-1$ \\
\hline & $5 \mathrm{~F} 11$ & $16.4 \mathrm{v}-\mathrm{x}$ & $33.61-q$ & $39.8 \mathrm{~h}-\mathrm{m}$ \\
\hline Dothiorella iberica & $5 \mathrm{G} 97$ & $13 \mathrm{v}-\mathrm{x}$ & $21 \mathrm{~s}-\mathrm{v}$ & $26 q-t$ \\
\hline \multirow[t]{2}{*}{ Lasiodiplodia citricola } & $6 \mathrm{I} 34$ & $59.5 \mathrm{a}$ & $53 \mathrm{a}-\mathrm{e}$ & $60 \mathrm{a}$ \\
\hline & $6 \mathrm{I} 35$ & $54 \mathrm{a}-\mathrm{d}$ & $58.5 \mathrm{a}$ & $59 a$ \\
\hline \multirow[t]{3}{*}{ Neofusicoccum mediterraneum } & $5 \mathrm{C} 87$ & $41 \mathrm{~h}-1$ & $55.5 \mathrm{a}-\mathrm{c}$ & $50 \mathrm{~b}-\mathrm{g}$ \\
\hline & $5 \mathrm{H} 09$ & $37.5 \mathrm{j}-\mathrm{O}$ & $39.0 \mathrm{i}-\mathrm{m}$ & $41.5 \mathrm{~h}-1$ \\
\hline & $5 \mathrm{H} 53$ & $40 \mathrm{~h}-1$ & $53.9 \mathrm{a}-\mathrm{d}$ & $38.5 \mathrm{i}-\mathrm{m}$ \\
\hline N. nonquaesitum & $5 \mathrm{~A} 04$ & $28.5 \mathrm{p}-\mathrm{s}$ & $41.5 \mathrm{~h}-1$ & $38 \mathrm{i}-\mathrm{n}$ \\
\hline \multirow[t]{3}{*}{ N. parvum } & 1L83 & $58 \mathrm{ab}$ & $60 \mathrm{a}$ & $60 \mathrm{a}$ \\
\hline & 1L87 & $54 \mathrm{a}-\mathrm{d}$ & $48 \mathrm{c}-\mathrm{h}$ & $60 \mathrm{a}$ \\
\hline & $2 \mathrm{E} 43$ & $57 \mathrm{ab}$ & $60 \mathrm{a}$ & $60 \mathrm{a}$ \\
\hline N. vitifusiforme & $5 \mathrm{H} 02$ & $20.5 \mathrm{~s}-\mathrm{v}$ & $31.1 \mathrm{o}-\mathrm{r}$ & $37.5 \mathrm{j}-\mathrm{o}$ \\
\hline Neoscytalidium dimidiatum & 2D57 & $38 \mathrm{i}-\mathrm{n}$ & $38 \mathrm{j}-\mathrm{O}$ & $46 \mathrm{~d}-\mathrm{n}$ \\
\hline Diaporthe neotheicola & $6 \mathrm{I} 30$ & $13.7 \mathrm{v}-\mathrm{x}$ & $16 v-x$ & $31.5 \mathrm{~m}-\mathrm{r}$ \\
\hline D. rhusicola & $6 \mathrm{I} 44$ & $14.1 \mathrm{v}-\mathrm{x}$ & $15.5 \mathrm{v}-\mathrm{x}$ & $20.5 \mathrm{~s}-\mathrm{V}$ \\
\hline Control & $\ldots$ & $9.9 w-x$ & $9.6 w-x$ & $9 \mathrm{x}$ \\
\hline
\end{tabular}

${ }^{\mathrm{z}}$ Numbers followed by different letters are significantly different $(P=0.05)$. 


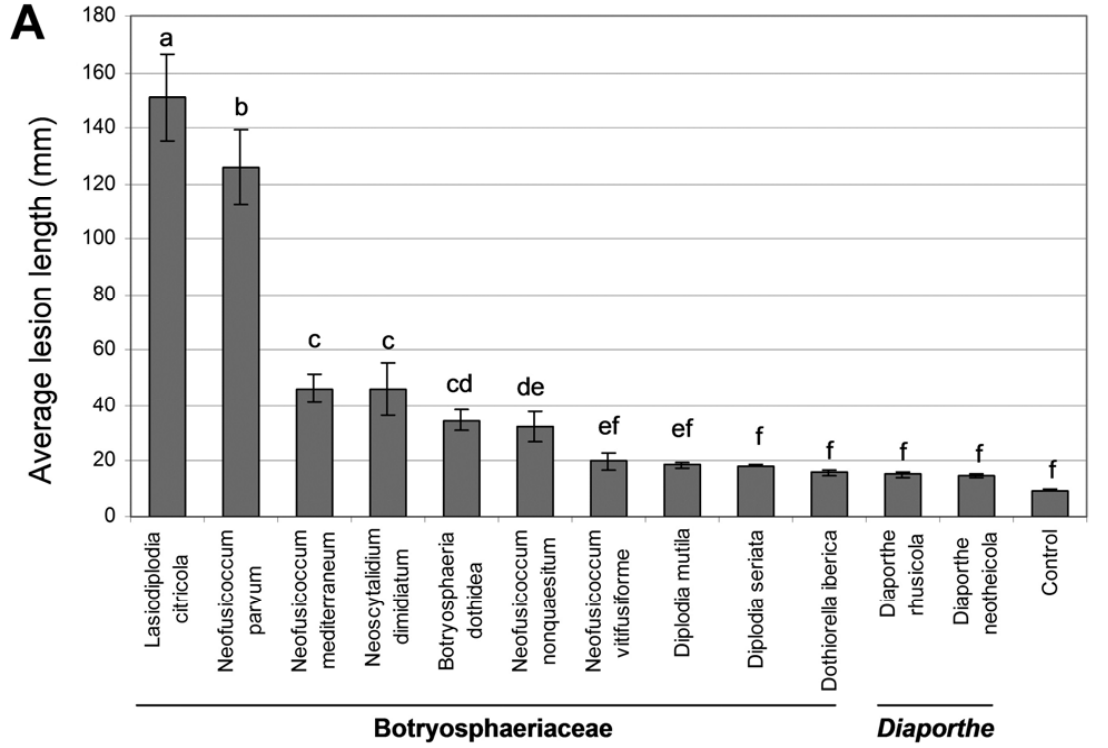

Botryosphaeriaceae

Treatments

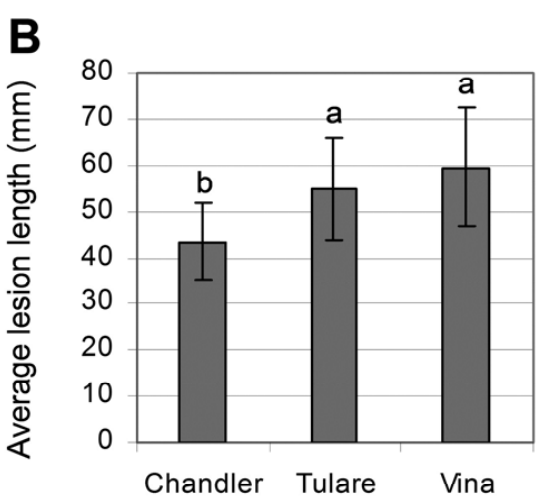

Cultivars

Fig. 7. A, Average lesion length $(\mathrm{mm})$ on attached walnut branches after inoculation with a mycelium plug of 10 Botryosphaeriaceae spp. and 2 species of Diaporthe. Inoculations were conducted on three walnut cultivars in two experiments. Bars topped with different letters indicate treatment means that are significantly different $(P=0.05)$ B, Average lesion length $(\mathrm{mm})$ on attached branches of three walnut cultivars after inoculation with a mycelium plug of each of 10 Botryosphaeriaceae spp. and $2 \mathrm{species}$ of Diaporthe (average of two experiments). Bars topped with different letters indicate significant differences among cultivars $(P=0.05)$.

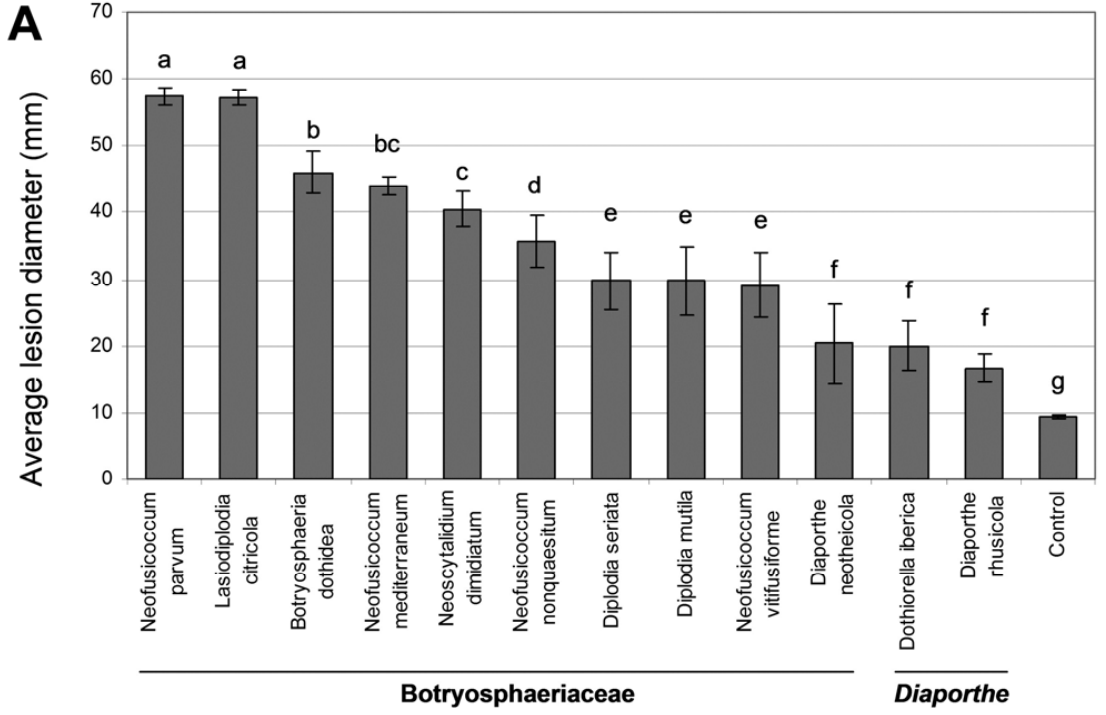

Treatments
B

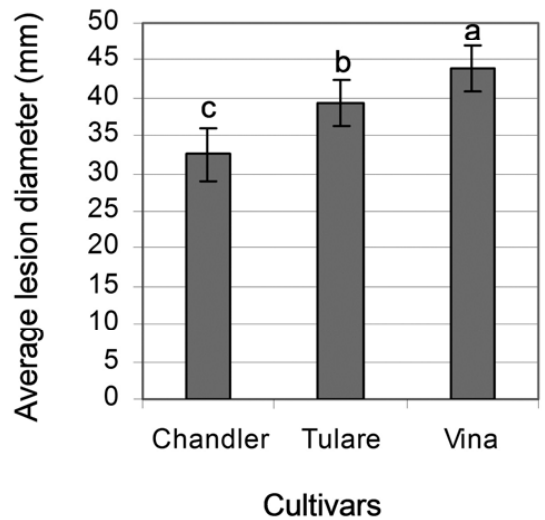

Fig. 8. A, Average lesion diameter $(\mathrm{mm})$ on hulls of attached fruit on the tree after inoculation with a mycelium plug of 10 Botryosphaeriaceae spp. and $2 \mathrm{species}$ of $\mathrm{Diaporthe}$. Inoculations were conducted on fruit of three walnut cultivars in two experiments. Bars topped with different letters indicate treatment means that are significantly different $(P=$ 0.05). B, Average lesion length $(\mathrm{mm})$ on hulls of attached walnut fruit of three walnut cultivars after inoculation with a mycelium plug of each of 10 Botryosphaeriaceae spp. and 2 species of Diaporthe (average of two experiments). Bars topped with different letters indicate significant differences among cultivars $(P=0.05)$.

amount (six isolates) of $N$. parvum was isolated from relatively few regions (Butte, Stanislaus, and Yolo Counties) but it is necessary to monitor the spread of this species to other regions in California.

$N$. mediterraneum on English walnut was first reported by Trouillas et al. (57) and caused twig and branch dieback. In their study, pathogenicity tests indicated that this species is highly virulent to English walnut trees (57). In our study, N. mediterraneum was the most frequently encountered species among all the species of Botryosphaeriaceae and Diaporthe, and was widely distributed in nearly all the counties of California where samples were collected. Inoculations showed that $N$. mediterraneum is intermediately virulent to English walnut among highly and less virulent species. Previous research showed that $N$. mediterraneum was common on other tree hosts in California, such as almond (28) and olive (41); in addition, inoculations indicated that it is intermediately to highly virulent to almond, grapevine, and olive $(28,41,60,64)$. These results suggest that future research on disease management should focus on this widespread and virulent pathogen of English walnut in California.

Botryosphaeria dothidea, Diplodia mutila, D. seriata, Dothiorella iberica, $N$. nonquaesitum, $N$. vitifusiforme, and Neoscytalidium dimidiatum were intermediately or weakly virulent to the tested English walnut cultivars in this study and they were not isolated frequently from English walnut in California. These species were also reported from other trees in California. B. dothidea has been isolated from almond (28), olive and pistachio (41), and many other hosts $(22,38)$. Diplodia mutila was isolated from avocado, Ilex sp. (28), grapevine, and Phoenix dactylifera (61). D. 
Table 7. Lesion lengths produced by species of Botryosphaeriaceae using two different inoculation methods; results show the average of three cultivars for all periodic inoculations of branches and fruit hulls on trees

\begin{tabular}{|c|c|c|c|c|c|}
\hline \multirow[b]{3}{*}{ Species } & \multirow[b]{3}{*}{ Isolate number } & \multicolumn{4}{|c|}{ Treatments $^{\mathrm{z}}$} \\
\hline & & \multicolumn{2}{|c|}{ Mycelium plugs } & \multicolumn{2}{|c|}{ Conidia suspension } \\
\hline & & On branches & On hulls & On branches & On hulls \\
\hline Botryosphaeria dothidea & $2 \mathrm{E} 55$ & $32.47 \mathrm{~d}$ & $53.57 \mathrm{bc}$ & $12.33 \mathrm{c}$ & $12.87 \mathrm{~cd}$ \\
\hline Lasiodiplodia citricola & $6 \mathrm{I} 35$ & $149 \mathrm{a}$ & $58.58 \mathrm{a}$ & $30.57 \mathrm{a}$ & $46.97 \mathrm{a}$ \\
\hline Neofusicoccum mediterraneum & $5 \mathrm{C} 87$ & $52.87 \mathrm{c}$ & $54.42 \mathrm{~b}$ & $13.52 \mathrm{~b}$ & $13.92 \mathrm{c}$ \\
\hline$N$. mediterraneum & $5 \mathrm{H} 53$ & $39.39 \mathrm{~d}$ & $52.03 \mathrm{c}$ & $12.25 \mathrm{c}$ & $12.9 \mathrm{~cd}$ \\
\hline N. parvum & $1 \mathrm{~L} 83$ & $84.93 \mathrm{~b}$ & $59.67 \mathrm{a}$ & $12.65 \mathrm{c}$ & $15.55 \mathrm{~b}$ \\
\hline Control & $\ldots$ & $9.57 \mathrm{e}$ & $9.77 \mathrm{~d}$ & $12.08 \mathrm{c}$ & $11.93 \mathrm{~d}$ \\
\hline
\end{tabular}

z Numbers followed by different letters are significantly different $(P=0.05)$.

seriata was recovered from almond, English walnut, pistachio, Prunus persica (28), grapevine (62), and olive (41). Dothiorella iberica was recovered from avocado (33), coast live oak (31), and grapevine (61). Neofusicoccum nonquaesitum was recovered from almond and $U$. californica (28), $N$. vitifusiforme was recovered from olive (65), and Neoscytalidium dimidiatum was recovered from fig (Ficus carica; 28). Because all of these species were not highly virulent to their hosts or not widespread among the regions where walnut are grown, they are not considered important pathogens of walnut presently. However, these fungi still need to be monitored carefully, because some of them may spread and act as important pathogens under a suitable environment.

Two species of Diaporthe (Diaporthe neotheicola and D. rhusicola) were identified in this study. D. neotheicola (synonym Phomopsis theicola) has been reported as a weak pathogen on several hosts, such as almond (19), Foeniculum vulgare (50), and kiwifruit (Actinidia deliciosa; 56). Furthermore, D. rhusicola was recently identified from the leaves of Rhus pendulina (17). Inoculation results indicated that these species are weak pathogens of English walnut in California.

Results in this study revealed that inoculation of English walnut branches and hulls with a mycelium plug of Botryosphaeriaceae and Diaporthe spp. resulted in much more severe disease than inoculation with a suspension of conidia. In the field, the anamorphic structures (pycnidia) were common, while the teleomorphic structures of Botryosphaeriaceae and Diaporthe spp. were rare on English walnut (T. J. Michailides, unpublished data). In the natural environment, the conidia of these species need water to exude from pycnidia and for dissemination and deposition on host tissue $(4,60)$. Because the germination of conidia is important for infection of English walnut, the conidia of the various species of Botryosphaeriaceae or Diaporthe will differ in their ability to infect walnut. Therefore, it is critical to determine whether there are compounds in walnut tissues that favor or inhibit the germination of Botryosphaeriaceae or Diaporthe conidia on the surface of walnut tissues.

In this study, in addition to California, species of Botryosphaeriaceae were also identified from other regions on English walnut, including Diplodia mutila and Neofusicoccum parvum from Spain and $B$. dothidea from Greece. Pathogenicity of these isolates on English walnut was not tested in this study, while the inoculation results for these species in this study suggest that these fungi in Spain and Greece should be monitored, because blight caused by species of Botryosphaeriaceae has caused significant yield losses in walnut grown in Spain and the disease has been reported in walnut grown in Greece (T. J. Michailides, unpublished data).

This study represents the first detailed research about the phylogeny, morphology, distribution, and pathogenicity of species of Botryosphaeriaceae on English walnut in California and a number of significant findings were discovered. A relatively large number of species of Botryosphaeriaceae and two species of Diaporthe were identified; species of Botryosphaeriaceae were widely distributed on English walnut in California. Most of the identified species were also reported from other fruit and nut trees; frequently, these tree species are adjacent or in close proximity to English walnut orchards throughout both the Sacramento and San Joaquin Valleys.
The occurrence of similar fungal species in all three major nut tree crops in California suggests that cross infection could occur among these crops. Inoculations revealed that all the species identified in this study are pathogenic to the English walnut branches or hulls, with $L$. citricola and $N$. parvum being the most virulent and $N$. mediterraneum being intermediately virulent, despite the fact that is the most widely distributed Botryosphaeriaceae sp. on walnut. It is essential that these pathogens be monitored carefully in order to help make decisions on disease management. Inoculation of the three English walnut cultivars used in this study further suggests that there may be differences in susceptibility or tolerance of the different English walnut cultivars. Therefore, specific control measures need to be developed for the highly susceptible English walnut cultivars in California.

\section{Acknowledgments}

This research was funded by a project of the California Walnut Board. We thank a large number of colleagues of the University of California Cooperative Extension for offering the diseased samples; and C. Solorio, A. Hiley, M. Luna, and R. Puckett for their valuable technical assistance in the laboratory and the field. We thank Ms. FeiFei Liu and Mr. GuoQing Li in the China Eucalypt Research Centre (CERC) for their assistance in the sequence submission.

\section{Literature Cited}

1. Abdollahzadeh, J., Javadi, A., Mohammadi, G. E., Zare, R., and Phillips, A. J. L. 2010. Phylogeny and morphology of four new species of Lasiodiplodia from Iran. Persoonia 25:1-10.

2. Adaskaveg, J. E., Forster, H., and Connell, J. H. 1999. First report of fruit rot and associated branch dieback of almond in California caused by a Phomopsis species tentatively identified as $P$. amygdali. Plant Dis. 83:1073.

3. Adesemoye, A. O., and Eskalen, A. 2011. First report of Spencermartinsia viticola, Neofusicoccum australe, and N. parvum causing branch canker of citrus in California. Plant Dis. 95:770.

4. Ahimera, N., Gisler, S., Morgan, D. P., and Michailides, T. J. 2004. Effects of single-drop impactions and natural and simulated rains on the dispersal of Botryosphaeria dothidea conidia. Phytopathology 94:1189-1197.

5. Alves, A., Correia, A., Luque, J., and Phillips, A. 2004. Botryosphaeria corticola, sp. nov. on Quercus species, with notes and description of Botryosphaeria stevensii and its anamorph, Diplodia mutila. Mycologia 96:598-613.

6. Alves, A., Correia A., and Phillips, A. J. L. 2006. Multi-gene genealogies and morphological data support Diplodia cupressi sp. nov., previously recognized as D. pinea $\mathrm{f}$. sp. cupressi, as a distinct species. Fungal Divers. 23:1-15.

7. Alves, A., Crous, P. W., Correia, A., and Phillips, A. J. L. 2008. Morphological and molecular data reveal cryptic speciation in Lasiodiplodia theobromae. Fungal Divers. 28:1-13.

8. Barr, M. E. 1987. Prodromus to Class Loculoascomycetes. Hamilton I. Newell, Inc., Amherst, MA.

9. Boriss, H., Brunke, H., and Kreith, M. 2006. Commodity Profile: English Walnuts. Agricultural Issues Center, University of California, Davis.

10. Carbone, I., Anderson, J. B., and Kohn, L. M. 1999. A method for designing primer sets for speciation studies in filamentous ascomycetes. Mycologia 3:553-556.

11. Chen, S. F., Fichtner, E., Morgan, D. P., and Michailides, T. J. 2013. First report of Lasiodiplodia citricola and Neoscytalidium dimidiatum causing death of graft union of English walnut in California. Plant Dis. 97:993.

12. Chen, S. F., Gryzenhout, M., Roux, J., Xie, Y. J., Wingfield, M. J., and Zhou, X. D. 2011. Novel species of Celoporthe from Eucalyptus and Syzygium trees in China and Indonesia. Mycologia 103:1384-1410.

13. Chen, S. F., Morgan, D. P., Beede, R. H., and Michailides, T. J. 2013. First report of Lasiodiplodia theobromae associated with stem canker of almond in California. Plant Dis. 97:994.

14. Chen, S. F., Morgan, D. P., Hasey, J. K., and Michailides, T. J. 2013. First 
report of Lasiodiplodia citricola associated with stem canker of peach in California, USA. J. Plant Pathol. Online publication. doi:10.4454/ JPP.V95I3.019

15. Chen, S. F., Pavlic, D., Roux, J., Xie, Y. J., Wingfield, M. J., and Zhou, X. D. 2011. Characterization of Botryosphaeriaceae from plantation-grown Eucalyptus species in South China. Plant Pathol. 60:739-751.

16. Chen, W. Q., Ntahimpera, N., Morgan, D. P., and Michailides, T. J. 2002. Mycoflora of Pistacia vera in the central valley, California. Mycotaxon 83:147-158.

17. Crous, P. W., Groenewald, J. Z., Shivas, R. G., Edwards, J., Seifert, K. A., Alfenas, A. C., Alfenas, R. F., Burgess, T. I., Carnegie, A. J., Hardy, G. E. St. J., Hiscock, N., Hüberli, D., Jung, T., Louis-Seize, G., Okada, G., Pereira, O. L., Stukely, M. J. C., Wang, W., White, G. P., Young, A. J., McTaggart, A. R., Pascoe, I. G., Porter, I. J., and Quaedvlieg, W. 2011. Fungal Planet description sheets: 69-91. Persoonia 26:108-156.

18. Crous, W. P., Wingfield, M. J., and Phillips, A. J. L. 2007. Neofusicoccum mediterraneum Crous, M.J. Wingf. \& A.J.L. Phillips, sp. nov. Fungal Planet 19.

19. Diogo, E. L. F., Santos, J. M., and Phillip, A. J. L. 2010. Phylogeny, morphology and pathogenicity of Diaporthe and Phomopsis species on almond in Portugal. Fungal Divers. 44:107-115.

20. Farr, D. F., Elliott, M., Rossman, A. Y., and Edmonds, R. L. 2005. Fusicoccum arbuti sp. nov. causing cankers on Pacific madrone in western North America with notes on Fusicoccum dimidiatum, the correct name for Scytalidium dimidiatum and Nattrassia mangiferae. Mycologia 97:730-741.

21. Food and Agriculture Organization of the United Nations (FAO). FAOSTAT FAO Statistics Division. http://faostat.fao.org/default.aspx

22. French, A. M. 1989. California Plant Disease Host Index. California Department of Food Agriculture, Sacramento.

23. Glass, N. L., and Donaldson, G. C. 1995. Development of primer sets designed for use with the PCR to amplify conserved genes from filamentous Ascomycetes. Appl. Environ. Microbiol. 61:1323-1330.

24. Gomes, R. R., Glienke, C., Videira, S. I. R., Lombard, L., Groenewald, J. Z., and Crous, P. W. 2013. Diaporthe: a genus of endophytic, saprobic and plant pathogenic fungi. Persoonia 31:1-41.

25. Guindon, S., and Gascuel, O. 2003. A simple, fast, and accurate algorithm to estimate large phylogenies by maximum likelihood. Syst. Biol. 52:696-704

26. Hawksworth, D. L. 2011. Naming Aspergillus species: progress towards one name for each species. Med. Mycol. 49:70-76.

27. Hyde, K. D., McKenzie, E. H. C., and KoKo, T. W. 2011. Towards incorporating anamorphic fungi in a natural classification-checklist and notes for 2010. Mycosphere 2:1-88.

28. Inderbitzin, P., Bostock, R. M., Trouillas, F. P., and Michailides, T. J. 2010. A six locus phylogeny reveals high species diversity in Botryosphaeriaceae from California almond. Mycologia 102:1350-1368.

29. Katoh, K., Misawa, K., Kuma, K., and Miyata, T. 2002. MAFFT: a novel method for rapid multiple sequence alignment based on fast Fourier transform. Nucleic Acids Res. 30:3059-3066.

30. Liu, J. K., Phookamsak, R., Doilom, M., Wikee, S., Li, Y.-M., Ariyawansha, H., Boonmee, S., Chomnunti, P., Dai, D.-Q., Bhat, J. D., Romero, A. I., Zhuang, W.-Y., Monkai, J., Jones, E. B. G., Chukeatirote, E., KoKo, T. W., Zhao, Y.-C., Wang, Y., and Hyde, K. D. 2012. Towards a natural classification of Botryosphaeriales. Fungal Divers. 57:149-210.

31. Lynch, S. C., Eskalen, A., Mayorquin, J. S., and Wang, D. H. 2013. Identification and pathogenicity of Botryosphaeriaceae species associated with coast live oak (Quercus agrifolia) decline in southern California. Mycologia 105:125-140

32. Ma, Z., and Michailides, T. J. 2002. Characterization of Botryosphaeria dothidea isolates collected from pistachio and other plant hosts in California. Phytopathology 92:519-526.

33. McDonald, V., and Eskalen, A. 2011. Botryosphaeriaceae species associated with avocado branch cankers in California. Plant Dis. 95:1465-1473.

34. McDonald, V., Lynch, S., and Eskalen, A. 2009. First report of Neofusicoccum australe, $N$. luteum, and $N$. parvum associated with avocado branch canker in California. Plant Dis. 93:967.

35. Mehl, J. W. M., Slippers, B., Roux, J., and Wingfield, M. J. 2011. Botryosphaeriaceae associated with Pterocarpus angolensis (kiaat) in South Africa. Mycologia 103:534-553.

36. Michailides, T. J. 1991. Pathogenicity, distribution, sources of inoculum, and infection courts of Botryosphaeria dothidea on pistachio. Phytopathology 81:566-573.

37. Michailides, T. J. 2003. Diseases of fig. Pages 253-273 in: Diseases of Tropical Fruit Crops. CABI, Wallingford, UK.

38. Michailides, T. J., and Morgan, D. P. 2004. Panicle and shoot blight of pistachio: a major threat to the California pistachio industry. APSnet Feature Story.

39. Michailides, T. J., Morgan, D. P., and Doster, M. A. 1995. Diseases of pistachio in California and their significance. In: 1st Int. Symp. Pistachio, Adana, Turkey. N. Kaska, A. B. Kuden, L. Ferguson, and T. Michailides, eds. ISHS Acta Hortic. 419:337-343.

40. Mohali, S., Slippers, B., and Wingfield, M. J. 2006. Two new Fusicoccum species from Acacia and Eucalyptus in Venezuela, based on morphology and DNA sequence data. Mycol. Res. 110:405-413.

41. Moral, J., Muñoz-Díez, C., González, N., Trapero, A., and Michailides, T. J. 2010. Characterization and pathogenicity of Botryosphaeriaceae species collected from olive and other hosts in Spain and California. Phytopathology 100:1340-1351.

42. Ogawa, J. M., and English, H. 1991. Disease of Temperate Zone Tree Fruit and Nut Crops. University of California, Division of Agriculture and Natural Resources, Oakland

43. Pavlic, D., Wingfield, M. J., Barber, P., Slippers, B., Hardy, G. E. St. J, and Burgess, T. I. 2008. Seven new species of the Botryosphaeriaceae from baobab and other native trees in Western Australia. Mycologia 100:851-866.

44. Phillips, A., Alves, A., Correia, A., and Luque, J. 2005. Two new species of Botryosphaeria with brown, 1-septate ascospores and Dothiorella anamorphs. Mycologia 97:513-529.

45. Phillips, A. J. L., Crous, P. W., and Alves, A. 2007. Diplodia seriata, the anamorph of "Botryosphaeria" obtusa. Fungal Divers. 25:141-155.

46. Posada. D., and Crandall, K. A. 1998. MODELTEST: testing the model of DNA substitution. Bioinformatics 14:817-818

47. Rayner, R.W. 1970. A Mycological Colour Chart. Commonwealth Mycological Institute and British Mycological Society, Kew, Surrey, UK.

48. Rossman, A. Y., Farr, D. F., and Castlebury, L. A. 2007. A review of the phylogeny and biology of the Diaporthales. Mycoscience 48:135-144.

49. Santos, J. M., Correia, V. G., and Phillips, A. J. L. 2010. Primers for matingtype diagnosis in Diaporthe and Phomopsis: their use in teleomorph induction in vitro and biological species definition. Fungal Biol. 114:255-270.

50. Santos, J. M., and Phillips. A. J. L. 2009. Resolving the complex of $D i$ aporthe (Phomopsis) species occurring on Foeniculum vulgare in Portugal. Fungal Divers. 34:111-125.

51. SAS Institute Inc. 2011. SAS/STAT Users Guide, Version 9.3. SAS Inc. Cary, NC.

52. Shenoy, B. D., Jeewon, R., and Hyde, K. D. 2007. Impact of DNA sequence data on the taxonomy of anamorphic fungi. Fungal Divers. 26:1-54.

53. Slippers, B., Crous, P. W., Denman, S., Coutinho, T. A., Wingfield, B. D. and Wingfield, M. J. 2004. Combined multiple gene genealogies and phenotypic characters differentiate several species previously identified as Botryosphaeria dothidea. Mycologia 96:83-101.

54. Slippers, B., and Wingfield, M. J. 2007. Botryosphaeriaceae as endophytes and latent pathogens of woody plants: diversity, ecology and impact. Fungal Biol. Rev. 21:90-106

55. Tamura, K., Dudley, J., Nei. M., and Kumar, S. 2007. MEGA4: molecular evolutionary genetics analysis (MEGA) software version 4.0. Mol. Biol. Evol. 24:1596-1599.

56. Thomidis, T., Exadaktylou, E., and Chen, S. F. 2013. Diaporthe neothe icola, a new threat for kiwifruit in Greece. Crop Prot. 47:35-40.

57. Trouillas, F. P., Úrbez-Torres, J. R., Peduto, F., and Gubler, W. D. 2010 First report of twig and branch dieback of English walnut (Juglans regia) caused by Neofusicoccum mediterraneum in California. Plant Dis. 94:1267.

58. Udayanga, D., Liu, X. Z., McKenzie, E. H. C., Chukeatirote, E., Bahkali, A. H. A., and Hyde, K. D. 2011. The genus Phomopsis: biology, applications, species concepts and names of common phytopathogens. Fungal Divers. 50:189-225.

59. Uecker, F. A. 1988. A world list of Phomopsis names with notes on nomenclature, morphology and biology. Contributions from the U.S. National Fungus Collection. Mycol. Mem. 13:9-12.

60. Úrbez-Torres, J. R., Battany, M., Bettiga, L. J., Gispert, C., McGourty, G., Roncoroni, J., Smith, R. J., Verdegaal, P., and Gubler, W. D. 2010. Botryosphaeriaceae species spore-trapping studies in California vineyards. Plant Dis. 94:717-724.

61. Úrbez-Torres, J. R., and Gubler, W. D. 2009. Pathogenicity of Botryosphaeriaceae species isolated from grapevine cankers in California. Plant Dis. 93:584-592.

62. Urbez-Torres, J. R., Leavitt. G. M., Guerrero, J. C., Guevara, J., and Gubler, W. D. 2008. Identification and pathogenicity of Lasiodiplodia theobromae and Diplodia seriata, the causal agents of bot canker disease of grapevines in Mexico. Plant Dis. 92:519-529.

63. Úrbez-Torres, J. R., Leavitt, G. M., Voegel, T. M., and Gubler, W. D. 2006 Identification and distribution of Botryosphaeria spp. associated with grapevine cankers in California. Plant Dis. 90:1490-1503.

64. Úrbez-Torres, J. R., Peduto, F., and Gubler, W. D. 2010. First report of grapevine cankers caused by Lasiodiplodia crassispora and Neofusicoccum mediterraneum in California. Plant Dis. 94:785.

65. Úrbez-Torres, J. R., Peduto, F., Vossen, P. M., Krueger, W. H., and Gubler, W. D. 2013. Olive twig and branch dieback: etiology, incidence, and distribution in California. Plant Dis. 97:231-244.

66. Van Niekerk, J. M., Crous, P.W., Groenewald, J. Z., Fourie, P. H., and Halleen, F. 2004. DNA phylogeny, morphology and pathogenicity of Botryosphaeria species on grapevines. Mycologia 96:781-798.

67. Van Niekerk, J. M., Groenewald, J. Z., Farr, D. F., Fourie, P. H., Halleen, F. and Crous, P. W. 2005. Reassessment of Phomopsis species on grapevines. Australas. Plant Pathol. 34:27-39.

68. White, T. J., Bruns, T., Lee, S., and Taylor, J. 1990. Amplification and direct sequencing of fungal ribosomal RNA genes for phylogenetics. Pages 315-322 in: PCR Protocols: a Guide to Methods and Applications. M. A. Innis, D. H Gelfand, J. J. Snisky, and T. J. White, eds. Academic Press, San Diego, CA.

69. Wingfield, M. J., De Beer, Z. W., Slippers, B., Wingfield, B., Groenewald, J. Z., Lombard, L., and Crous, P. W. 2012. One fungus, one name promotes progressive plant pathology. Mol. Plant Pathol. 13:604-613. 